Supporting information for:

\title{
Syntheses of Soluble, $\pi$-Stacking Tetracene Derivatives
}

\author{
Zhihua Chen, Peter Müller, Timothy M. Swager* \\ Department of Chemistry, Massachusetts Institute of Technology, \\ Cambridge, Massachusetts 02139 \\ tswager@mit.edu
}

Details of experimental procedures:

UV-vis absorption spectra:

page $S 1-S 7$

Extra packing diagrams:

page $S 8$

NMR spectra:

General: NMR $\left({ }^{1} \mathrm{H},{ }^{13} \mathrm{C},{ }^{19} \mathrm{~F}\right)$ spectra were recorded on Varian Mercury-300 MHz, Varian Inova-500 $\mathrm{MHz}$ or Bruker Advance-400 MHz spectrometers. The ${ }^{1} \mathrm{H}$ and ${ }^{13} \mathrm{C}$ chemical shifts are given in unit of $\delta$ $(\mathrm{ppm})$ relative the tetramethylsilane $(\mathrm{TMS})$ where $\delta(\mathrm{TMS})=0$, and referenced to the residual solvent.

${ }^{19} \mathrm{~F}$ NMR chemical shifts are reported relative to trichlorofluoromethane or hexafluorobenzene as the reference. High-resolution mass spectra (HRMS) were obtained on a Bruker Daltonics APED II 3T FTICR-MS using electron impact ionization (EI). The X-ray crystal structure was determined with a Siemens Platform three-circle diffractometer coupled to a Bruker-AXS Smart Apex CCD detector with graphite-monochromated Mo K $\alpha$ radiation $(\lambda=0.71073 \AA)$, performing $\varphi$ - and $\omega$-scans. All structures were solved by direct methods using SHELXS [Sheldrick, G. M., Acta Cryst. Sect. A (1990), 46, 467.] and refined against $F^{2}$ on all data by full-matrix least squares with SHELXL-97 [Sheldrick, G. M. SHELXL 97, Universität Göttingen, Göttingen, Germany, 1997.]. All non-hydrogen atoms were refined anisotropically. All hydrogen atoms were included into the model at geometrically calculated positions and refined using a riding model. The isotropic displacement parameters of all hydrogen atoms were fixed to 1.2 times the $U$ value of the atoms they are linked to (1.5 times for methyl groups). The electrochemistry studies were performed using Autolab PGSTAT 10 potentiostat (Eco Chemie) in a three-electrode cell configuration under nitrogen atmosphere. Cyclic voltammetry (CV) experiments were carried out in $0.1 \mathrm{M}$ tetrabutylammonium hexafluorophosphate $\left(\mathrm{TBAPF}_{6}\right)$ supporting electrolyte in $\mathrm{CH}_{2} \mathrm{Cl}_{2}$. A platinum button (1.6 mm in diameter) and platinum gauze were used as the working and counter electrodes, respectively. The potential was measured against a $\mathrm{Ag} / \mathrm{AgNO}_{3}(10 \mathrm{mM})$ in $0.1 \mathrm{M}$ $\mathrm{TBAPF}_{6}$ in $\mathrm{CH}_{3} \mathrm{CN}$. The reported potentials are versus the ferrocene/ferrocenium $\left(\mathrm{Fc} / \mathrm{Fc}^{+}\right)$couple with 
observed half-wave potentials between $250 \mathrm{mV}$ and $300 \mathrm{mV}$, obtained by adding a crystal of ferrocene to the solution. UV-vis spectra were obtained from Hewllett-Packard 8452A diode array UV-visible spectrophotometer.

Materials: Anhydrous tetrahydrofuran (THF), toluene, $\mathrm{CH}_{3} \mathrm{CN}$ and $\mathrm{CH}_{2} \mathrm{Cl}_{2}$ were purchased from Aldrich Chemical Co., Inc. Furan was distilled from $\mathrm{K}_{2} \mathrm{CO}_{3}$ prior to use. $\mathrm{N}$-Bromosuccinimide (NBS) was recrystallized from water. 1,2,3,4-tetrafluoro-5,8-dihydro-5,8- $N$-methylaminonaphthalene (1), ${ }^{1}$ 6,7dibromo-1,4-naphthoquinone (6), ${ }^{2}$ 1,2,4,5-tetrabromo-3,6-dioctylbenzene $(\mathbf{9 b})^{3}$ and 2,5-dioctylfuran ${ }^{4}$ were prepared following literature procedures. All other reagent grade starting materials were purchased from Aldrich, Lancaster, or Alfa Aesar, and used without further purification. Silica gel (40-63 $\mu \mathrm{m})$ was obtained from SiliCycle. Neutral alumina (58 angstroms) was purchased from Alfa Aesar and basic alumina (chromatographic grade, 80-325 mesh) was purchased from EMD Chemicals Co..

\section{Syntheses:}

\section{General procedure for synthesis of $4 a-d:{ }^{5}$}

A solution of 3,6-(di-2-pyridyl)-1,2,4,5-tetrazine (1 eq.) and 1,2,3,4-tetrafluoro-5,8-dihydro-5,8- $\mathrm{N}$ methylaminonaphthalene 1 ( 1 eq.) in $50 \mathrm{~mL} \mathrm{CH}_{2} \mathrm{Cl}_{2}$ was stirred overnight under $\mathrm{Ar}$ at room temperature. The mixture was filtered through a short column of neutral $\mathrm{Al}_{2} \mathrm{O}_{3}$. The filtrate was concentrated in vacuo, and the slightly yellow residue was dried under vacuum. Dibromonaphthalene 3a-d (0.8 eq.) and anhydrous THF $(50 \mathrm{~mL})$ were then added. Under Ar atmosphere, a solution of phenyllithium (1.6 M in cyclohexane/ether; 1 eq.) was then added dropwise to the above mixture at $0{ }^{\circ} \mathrm{C}$ over 3 hours. After addition, the mixture was stirred at $0{ }^{\circ} \mathrm{C}$ for an additional 1 hour, and then allowed to warm to room temperature slowly and stirred overnight. The mixture was poured into water and extracted by $\mathrm{CHCl}_{3}$. The organic layer was washed by brine and dried over $\mathrm{Na}_{2} \mathrm{SO}_{4}$. Solvent was removed in vacuo. Purification by column chromatography (basic $\mathrm{Al}_{2} \mathrm{O}_{3}$ ) afforded colorless or slightly yellow solids.

13-Methyl-1,2,3,4-tetrafluoro-7,10-bis(hexyloxy)-5,12-dihydronaphthacene-5,12-imine (4a): This compound was prepared by following the general procedure described above, employing 1 (1.7 g, 7.4 $\mathrm{mmol}), 3 \mathrm{a}(2.5 \mathrm{~g}, 5.2 \mathrm{mmol})$, phenyllithium (1.6 M in cyclohexane/ether, $4.0 \mathrm{~mL}, 6.4 \mathrm{mmol})$, THF (130 $\mathrm{mL})$. The common workup and chromatography afforded $1.1 \mathrm{~g}$ of $\mathbf{4 a}$ as a white/tan solid $(40 \%) .{ }^{1} \mathrm{H}$ NMR (300 MHz, CDCl $) 8.17$ (s, 2H), $6.72(\mathrm{~s}, 2 \mathrm{H}), 5.37$ (s, 2H), 4.05 (m, 4H), 2.29 (s, 3H), 1.91 (m, 
4H), $1.56(\mathrm{~m}, 4 \mathrm{H}), 1.41(\mathrm{~m}, 8 \mathrm{H}), 0.95(\mathrm{t}, 6 \mathrm{H}) .{ }^{19} \mathrm{~F}$ NMR (282 MHz, CDCl 3 ) -140.9 (br), -142.2 (br), 153.8 (br), -156.2 (br). ${ }^{13} \mathrm{C} \mathrm{NMR}\left(125 \mathrm{MHz}, \mathrm{CDCl}_{3}\right)$ 149.2, 125.1, 105.8, 69.8, 68.8, 36.5, 31.9, 29.6, 26.2, 22.8, 14.3. HRMS calcd for $\mathrm{C}_{31} \mathrm{H}_{35} \mathrm{~F}_{4} \mathrm{NO}_{2}\left(\mathrm{M}^{+}\right)$529.2598, found 529.2590.

13-Methyl-1,2,3,4-tetrafluoro-6,11-bis(hexyloxy)-5,12-dihydronaphthacene-5,12-imine (4b): This compound was prepared by following the general procedure described above, employing 1 (0.77 g, 3.4 mmol), 3b (1.2 g, $2.5 \mathrm{mmol}$ ), phenyllithium (1.6 M in cyclohexane/ether, $2.6 \mathrm{~mL}, 4.2 \mathrm{mmol})$, THF (50 $\mathrm{mL})$. The common workup and chromatography afforded $0.7 \mathrm{~g}$ of $\mathbf{4 b}$ as colorless crystals $(55 \%)$. ${ }^{1} \mathrm{H}$ NMR (300 MHz, $\left.\mathrm{CDCl}_{3}\right) 8.12(\mathrm{dd}, 2 \mathrm{H}), 7.50(\mathrm{dd}, 2 \mathrm{H}), 5.63(\mathrm{~s}, 2 \mathrm{H}), 4.25(\mathrm{~m}, 2 \mathrm{H}), 4.07(\mathrm{~m}, 2 \mathrm{H}), 2.28(\mathrm{~s}$, 2H), $1.95(\mathrm{~m}, 4 \mathrm{H}), 1.61(\mathrm{~m}, 4 \mathrm{H}), 1.43(\mathrm{~m}, 8 \mathrm{H}), 0.97(\mathrm{t}, 6 \mathrm{H}) .{ }^{19} \mathrm{~F}$ NMR $\left(282 \mathrm{MHz}, \mathrm{CDCl}_{3}\right)-144.2$ (br), 145.4 (br), -156.9 (br), -159.2 (br). ${ }^{13} \mathrm{C} \mathrm{NMR}$ (125 MHz, $\mathrm{CDCl}_{3}$ ) 128.8, 126.6, 122.7, 74.8, 67.8, 36.5, 31.8, 30.6, 26.0, 22.8, 14.2. HRMS calcd for $\mathrm{C}_{31} \mathrm{H}_{35} \mathrm{~F}_{4} \mathrm{NO}_{2}\left(\mathrm{M}^{+}\right)$529.2598, found 529.2597.

13-Methyl-1,2,3,4-tetrafluoro-7,10-dioctyl-5,12-dihydronaphthacene-5,12-imine (4c): This compound was prepared by following the general procedure described above, employing 1 (0.73 g, 3.2 mmol), 3c (1.2 g, $2.4 \mathrm{mmol})$, phenyllithium (1.6 M in cyclohexane/ether, $2.0 \mathrm{~mL}, 3.2 \mathrm{mmol}$ ), THF (60 $\mathrm{mL})$. The common workup and chromatography afforded $0.6 \mathrm{~g}$ of $\mathbf{4 c}$ as a white/tan solid $(45 \%) .{ }^{1} \mathrm{H}$ NMR (300 MHz, $\left.\mathrm{CDCl}_{3}\right) 8.00(\mathrm{~s}, 2 \mathrm{H}), 7.24(\mathrm{~s}, 2 \mathrm{H}), 5.41(\mathrm{~s}, 2 \mathrm{H}), 3.00(\mathrm{~m}, 4 \mathrm{H}), 2.33(\mathrm{~s}, 3 \mathrm{H}), 1.72(\mathrm{~m}$, 4H), 1.31 (m, 20H), 0.92 (t, 6H). ${ }^{19} \mathrm{~F}$ NMR (282 MHz, CDCl 3 ) -141.0 (br), -142.2 (br), -153.4 (br), 155.9 (br). ${ }^{13} \mathrm{C}$ NMR (125 MHz, $\left.\mathrm{CDCl}_{3}\right)$ 137.5, 131.1, 126.6, 70.0, 36.5, 33.5, 32.1, 31.1, 30.0, 29.7, 29.5, 22.9, 14.3. HRMS calcd for $\mathrm{C}_{35} \mathrm{H}_{43} \mathrm{~F}_{4} \mathrm{~N}\left(\mathrm{M}^{+}\right)$553.3326, found 553.3334.

13-Methyl-1,2,3,4-tetrafluoro-6,11-dioctyl-5,12-dihydronaphthacene-5,12-imine (4d): This compound was prepared by following the general procedure described above, employing 1 (0.81 g, 3.53 mmol), 3d (1.44 g, $2.8 \mathrm{mmol}$ ), phenyllithium (1.6 M in cyclohexane/ether, $2.1 \mathrm{~mL}, 3.4 \mathrm{mmol})$, THF (50 $\mathrm{mL})$. The common workup and chromatography afforded $0.66 \mathrm{~g}$ of $\mathbf{4 d}$ as a white/tan solid $(42 \%) .{ }^{1} \mathrm{H}$ NMR (300 MHz, $\left.\mathrm{CDCl}_{3}\right) 7.96(\mathrm{dd}, 2 \mathrm{H}), 7.48(\mathrm{dd}, 2 \mathrm{H}), 5.48(\mathrm{~s}, 2 \mathrm{H}), 3.07(\mathrm{t}, 4 \mathrm{H}), 2.31$ (s, 3H), $1.63(\mathrm{~m}$, $4 \mathrm{H}), 1.51(\mathrm{~m}, 4 \mathrm{H}), 1.31(\mathrm{~m}, 16), 0.91(\mathrm{t}, 6 \mathrm{H}) .{ }^{19} \mathrm{~F}$ NMR (282 MHz, $\left.\mathrm{CDCl}_{3}\right)-140.7$ (br), -142.1 (br), 153.6 (br), -156.0 (br). ${ }^{13} \mathrm{C}$ NMR (125 MHz, $\mathrm{CDCl}_{3}$ ) 131.4, 125.9, 124.8, 69.1, 36.5, 32.1, 31.3, 30.4, 29.9, 29.7, 29.5, 22.9, 14.3. HRMS calcd for $\mathrm{C}_{35} \mathrm{H}_{43} \mathrm{~F}_{4} \mathrm{~N}\left(\mathrm{M}^{+}\right)$553.3326, found 553.3320.

General procedure for preparation of 5a-d: $:^{5,6}$ 
Under Ar, benzyltriethylammonium chloride $(40 \mathrm{mg})$ was added in one portion to a stirred solution of imine (4a-d) $(1.5 \mathrm{mmol})$ in chloroform $(40 \mathrm{~mL})$. An aqueous $\mathrm{NaOH}$ solution $(50 \%, 2 \mathrm{~mL})$ was then added dropwise. The resulting mixture was stirred at room temperature overnight. The reaction mixture was poured into an aqueous $\mathrm{HCl}$ solution $(3 \mathrm{M}, 80 \mathrm{~mL})$ and extracted by $\mathrm{CHCl}_{3}$. The organic layer was washed by water and brine in sequence, and dried over $\mathrm{K}_{2} \mathrm{CO}_{3}$. The solvent was removed in vacuo. Purification by flash column chromatography (Silica gel) and recrystallization from hexane afforded red or orange crystals.

1,2,3,4-tetrafluoro-7,10-bis(hexyloxy)tetracene (5a): This compound was prepared by following the general procedure described above, employing 4a (1.09 g, $2.06 \mathrm{mmol})$, benzyltriethylammonium chloride $(50 \mathrm{mg}), \mathrm{NaOH}(50 \%$ aqueous, $1.2 \mathrm{~mL}), \mathrm{CHCl}_{3}(50 \mathrm{~mL})$. The common workup, chromatography and recrystallization afforded $0.45 \mathrm{~g}$ of $\mathbf{5 a}$ as red needle-like crystals (44\%). ${ }^{1} \mathrm{H}$ NMR (300 MHz, $\left.\mathrm{CDCl}_{3}\right) 8.61(\mathrm{~s}, 2 \mathrm{H}), 8.39$ (s, 2H), $6.44(\mathrm{~s}, 2 \mathrm{H}), 4.11(\mathrm{t}, 4 \mathrm{H}), 2.02(\mathrm{~m}, 4 \mathrm{H}), 1.67(\mathrm{~m}, 4 \mathrm{H}), 1.50$ (m, 8H), $1.02(\mathrm{t}, 6 \mathrm{H}) .{ }^{19} \mathrm{~F}$ NMR (282 MHz, $\left.\mathrm{CDCl}_{3}\right)-149.8(\mathrm{~m}, 2 \mathrm{~F}),-158.8(\mathrm{~m}, 2 \mathrm{~F}) .{ }^{13} \mathrm{C}$ NMR $(100 \mathrm{MHz}$, $\left.\mathrm{CDCl}_{3}\right) 148.3,128.9,126.5,121.1,120.0,101.7,68.4,32.0,29.6,26.3,23.0,14.4$. HRMS calcd for $\mathrm{C}_{30} \mathrm{H}_{32} \mathrm{~F}_{4} \mathrm{O}_{2}\left(\mathrm{M}^{+}\right)$500.2333, found 500.2325.

1,2,3,4-tetrafluoro-6,11-bis(hexyloxy)tetracene (5b): This compound was prepared by following the general procedure described above, employing $4 \mathbf{b}(0.69 \mathrm{~g}, 1.3 \mathrm{mmol})$, benzyltriethylammonium chloride (50 $\mathrm{mg}), \mathrm{NaOH}(50 \%$ aqueous, $0.9 \mathrm{~mL}), \mathrm{CHCl}_{3}(40 \mathrm{~mL})$. The common workup, chromatography and recrystallization afforded $0.42 \mathrm{~g}$ of $\mathbf{5 b}$ as red needle-like crystals $(64 \%) .{ }^{1} \mathrm{H}$ NMR $\left(300 \mathrm{MHz}, \mathrm{CDCl}_{3}\right)$ 9.09 (s, 2H), 8.29 (dd, 2H), $7.48(\mathrm{dd}, 2 \mathrm{H}), 4.26(\mathrm{t}, 4 \mathrm{H}), 2.11(\mathrm{~m}, 4 \mathrm{H}), 1.75(\mathrm{~m}, 4 \mathrm{H}), 1.49(\mathrm{~m}, 8 \mathrm{H}), 1.00(\mathrm{t}$, 6H). ${ }^{19} \mathrm{~F}$ NMR (282 MHz, $\left.\mathrm{CDCl}_{3}\right)-149.0$ (m, 2F), -157.8 (m, 2F). ${ }^{13} \mathrm{C}$ NMR (125 MHz, $\left.\mathrm{CDCl}_{3}\right)$ 147.9, 125.9, 125.3, 124.2, 123.0, 115.4, 76.8, 32.0, 30.9, 26.2, 23.0, 14.3. HRMS calcd for $\mathrm{C}_{30} \mathrm{H}_{32} \mathrm{~F}_{4} \mathrm{O}_{2}\left(\mathrm{M}^{+}\right)$ 500.2333 , found 500.2329 .

1,2,3,4-tetrafluoro-7,10-dioctyltetracene (5c): This compound was prepared by following the general procedure described above, employing $4 \mathbf{c}(0.6 \mathrm{~g}, 1.08 \mathrm{mmol})$, benzyltriethylammonium chloride (40 $\mathrm{mg}), \mathrm{NaOH}(50 \%$ aqueous, $0.8 \mathrm{~mL}), \mathrm{CHCl}_{3}(30 \mathrm{~mL})$. The common workup, chromatography and recrystallization afforded $0.26 \mathrm{~g}$ of $\mathbf{5 c}$ as red/orange crystals $(45 \%) .{ }^{1} \mathrm{H}$ NMR $\left(300 \mathrm{MHz}, \mathrm{CDCl}_{3}\right) 8.63$ (s, 2H), 8.60 (s, 2H), 7.19 (s, 2H), $3.10(\mathrm{t}, 4 \mathrm{H}), 1.85(\mathrm{~m}, 4 \mathrm{H}), 1.54(\mathrm{~m}, 4 \mathrm{H}), 1.34(\mathrm{~m}, 16), 0.93(\mathrm{t}, 6 \mathrm{H}) .{ }^{19} \mathrm{~F}$ 
NMR (282 MHz, $\left.\mathrm{CDCl}_{3}\right)$-149.5 (m, 2F), -158.4 (m, 2F) ${ }^{13} \mathrm{C}$ NMR (100 MHz, $\left.\mathrm{CDCl}_{3}\right)$ 137.0, 132.1, 129.0, 125.2, 123.6, 120.1, 33.4, 32.2, 30.4, 30.2, 29.8, 29.6, 23.0, 14.4. HRMS calcd for $\mathrm{C}_{34} \mathrm{H}_{40} \mathrm{~F}_{4}\left(\mathrm{M}^{+}\right)$ 524.3061 , found 524.3055.

1,2,3,4-tetrafluoro-6,11-dioctyltetracene (5d): This compound was prepared by following the general procedure described above, employing $4 \mathbf{d}$ (0.65 g, $1.18 \mathrm{mmol})$, benzyltriethylammonium chloride (40 $\mathrm{mg}), \mathrm{NaOH}(50 \%$ aqueous, $0.9 \mathrm{~mL}), \mathrm{CHCl}_{3}(40 \mathrm{~mL})$. The common workup, chromatography and recrystallization afforded $0.22 \mathrm{~g}$ of $\mathbf{5 d}$ as red/orange crystals $(35 \%) .{ }^{1} \mathrm{H} \mathrm{NMR}\left(300 \mathrm{MHz}, \mathrm{CDCl}_{3}\right) 8.95(\mathrm{~s}$, 2H), $8.27(\mathrm{dd}, 2 \mathrm{H}) 7.50(\mathrm{dd}, 2 \mathrm{H}) 3.66(\mathrm{t}, 4 \mathrm{H}), 1.86(\mathrm{~m}, 4 \mathrm{H}), 1.65(\mathrm{~m}, 4 \mathrm{H}), 1.46(\mathrm{~m}, 4 \mathrm{H}) 1.33(\mathrm{~m}, 12 \mathrm{H})$, 0.92(t, 6H). ${ }^{19} \mathrm{~F}$ NMR (282 MHz, $\left.\mathrm{CDCl}_{3}\right)-150.0(\mathrm{~m}, 2 \mathrm{~F}),-158.4(\mathrm{~m}, 2 \mathrm{~F}) .{ }^{13} \mathrm{C} \mathrm{NMR}\left(75 \mathrm{MHz}, \mathrm{CDCl}_{3}\right)$ 134.7, 129.8, 128.1, 125.8, 125.6, 117.2, 32.1, 31.6, 30.5, 29.7, 29.6, 28.7. HRMS calcd for $\mathrm{C}_{34} \mathrm{H}_{40} \mathrm{~F}_{4}$ $\left(\mathrm{M}^{+}\right)$524.3061, found 524.3068.

6,7-dibromo-1,4-bis(hexyloxy)naphthalene (3a): A mixture of 6 (4.3 g, $13.6 \mathrm{mmol})$ and $\mathrm{Na}_{2} \mathrm{~S}_{2} \mathrm{O}_{4}(35 \mathrm{~g})$ in $300 \mathrm{~mL}$ water and $500 \mathrm{~mL}$ ethyl ether was vigorously shaken periodically for about one hour. Organic layer was separated, washed by brine and dried over $\mathrm{Na}_{2} \mathrm{SO}_{4}$. The solvent was removed in vacuo, leading to slight yellow solid. After drying in vacuum, the product was used directly in the next step. Under Ar, $250 \mathrm{~mL}$ DMF was added to a mixture of the solid product, $\mathrm{K}_{2} \mathrm{CO}_{3}(18 \mathrm{~g}, 130 \mathrm{mmol})$ and 18crown-6 $(0.1 \mathrm{~g})$. After stirring for 10 minutes at room temperature, 1-iodohexane $(8 \mathrm{~mL}, 54.2 \mathrm{mmol})$ was added. The resulting mixture was then heated to $85{ }^{\circ} \mathrm{C}$ and stirred at that temperature for 4 days. After cooling, the mixture was poured into water and extracted by $\mathrm{CH}_{2} \mathrm{Cl}_{2}$. The organic layer was washed by dilute aqueous $\mathrm{NH}_{4} \mathrm{Cl}$ solution, water and brine in sequence, and then dried over $\mathrm{MgSO}_{4}$ and concentrated in vacuo. Purification by column chromatography (Silica gel, neat hexane ramping to $\mathrm{CH}_{2} \mathrm{Cl}_{2}$ :hexane $\left.=1: 9\right)$ and recrystallization from hexane yielded colorless crystals $(4.7 \mathrm{~g}, 71 \%)$. ${ }^{1} \mathrm{H}$ NMR (400 MHz, $\left.\mathrm{CDCl}_{3}\right) 8.48(\mathrm{~s}, 2 \mathrm{H}), 6.68(\mathrm{~s}, 2 \mathrm{H}), 4.05(\mathrm{t}, 4 \mathrm{H}), 1.90(\mathrm{~m}, 4 \mathrm{H}), 1.54(\mathrm{~m}, 4 \mathrm{H}), 1.40(\mathrm{~m}$, 8H), 0.95 (m, 6H). ${ }^{13} \mathrm{C}$ NMR (100 MHz, $\left.\mathrm{CDCl}_{3}\right)$ 147.8, 127.2, 126.4, 122.2, 105.7, 68.8, 31.8, 29.4, 26.1, 22.8, 14.3. HRMS calcd for $\mathrm{C}_{22} \mathrm{H}_{30} \mathrm{Br}_{2} \mathrm{O}_{2}\left(\mathrm{M}^{+}\right)$484.0607, found 484.0613.

1,4-bis(hexyloxy)naphthalene (8): This compound was prepared by following the procedure as described for 3a, employing 1,4-naphthoquinone (14.8 g, $93.5 \mathrm{mmol}), \mathrm{Na}_{2} \mathrm{~S}_{2} \mathrm{O}_{4}(76 \mathrm{~g}), \mathrm{K}_{2} \mathrm{CO}_{3}(119 \mathrm{~g}$, $862 \mathrm{mmol}), 18$-crown-6 (0.13 g), 1-iodohexane (38 ml, $260 \mathrm{~mol})$ and DMF (350 mL). The usual workup and recrystallization (from methanol) gave $21.3 \mathrm{~g}$ of $\mathbf{8}$ as colorless crystals $(73 \%) .{ }^{1} \mathrm{H}$ NMR $(400 \mathrm{MHz}$, 
$\left.\mathrm{CDCl}_{3}\right) 8.26(\mathrm{dd}, 2 \mathrm{H}), 7.51(\mathrm{dd}, 2 \mathrm{H}), 6.70(\mathrm{~s}, 2 \mathrm{H}), 4.09(\mathrm{t}, 4 \mathrm{H}), 1.92(\mathrm{~m}, 4 \mathrm{H}), 1.58(\mathrm{~m}, 4 \mathrm{H}), 1.41(\mathrm{~m}, 8 \mathrm{H})$, $0.96(\mathrm{t}, 6 \mathrm{H}) .{ }^{13} \mathrm{C} \mathrm{NMR}\left(100 \mathrm{MHz}, \mathrm{CDCl}_{3}\right)$ 149.0, 126.8, 125.8, 122.1, 104.5, 68.7, 31.9, 29.6, 26.2, 22.9, 14.3. HRMS calcd for $\mathrm{C}_{22} \mathrm{H}_{32} \mathrm{O}_{2}\left(\mathrm{M}^{+}\right) 328.2397$, found 328.2393.

2,3-dibromo-1,4-bis(hexyloxy)naphthalene (3b): A mixture of 8 (5.19 g, $15.8 \mathrm{mmol})$ and NBS (6.2 g, $34.8 \mathrm{mmol}$ ) in $100 \mathrm{~mL} \mathrm{CH}_{2} \mathrm{Cl}_{2}$ was stirred at room temperature for 24 hours. The reaction mixture was washed with a dilute $\mathrm{Na}_{2} \mathrm{~S}_{2} \mathrm{O}_{4}$ aqueous solution and brine. The organic layer was dried over $\mathrm{Na}_{2} \mathrm{SO}_{4}$ and concentrated in vacuo. Purification by column chromatography (Silica gel, hexane: $\mathrm{CH}_{2} \mathrm{Cl}_{2}=4: 1$ ) afforded a colorless solid (6.65 g, 87\%). ${ }^{1} \mathrm{H}$ NMR (300 MHz, $\left.\mathrm{CDCl}_{3}\right) 8.08$ (dd, 2H), 7.57 (dd, 2H), 4.06 $(\mathrm{t}, 4 \mathrm{H}), 1.97(\mathrm{~m}, 4 \mathrm{H}), 1.60(\mathrm{~m}, 4 \mathrm{H}), 1.41(\mathrm{~m}, 8 \mathrm{H}), 0.95(\mathrm{t}, 6 \mathrm{H}) .{ }^{13} \mathrm{C}$ NMR $\left(125 \mathrm{MHz}, \mathrm{CDCl}_{3}\right)$ 150.4, 128.7, 127.4, 123.0, 116.6, 74.7, 31.9, 30.4, 25.9, 22.9, 14.3. HRMS calcd for $\mathrm{C}_{22} \mathrm{H}_{30} \mathrm{Br}_{2} \mathrm{O}_{2}\left(\mathrm{M}^{+}\right)$ 484.0607, found 484.0599 .

1,4-epoxy-1,4-dihydro-6,7-dibromo-1,4-dioctylnaphthalene (10a): To a stirred solution of 2,5dioctylfuran (10.7 g, $36.6 \mathrm{mmol})$ and 1,2,4,5-tetrabromobenzene (9a) (9.0 g, $22.9 \mathrm{mmol})$ in $500 \mathrm{~mL}$ anhydrous toluene under Ar at $0{ }^{\circ} \mathrm{C}$ was added a solution of $n$-butyllithium ( $n$-BuLi) (1.6 M in hexane, $18.6 \mathrm{~mL}, 29.8 \mathrm{mmol}$ ) dropwise over 6 hours via a syringe pump. After the addition of $n$-BuLi, the reaction mixture was stirred at $0{ }^{\circ} \mathrm{C}$ for additional 2 hours, and then allowed to warm to room temperature slowly and stirred overnight. The reaction was quenched by the slow addition of methanol $(5 \mathrm{~mL})$. The resulting mixture was filtered through a pad of celite. The solvent was removed in vacuo. Purification by column chromatography (silica gel, neat hexane then hexane: $\mathrm{CHCl}_{3}=5: 1$ ) yielded colorless oil as clean product (7.75 g, 64\%). ${ }^{1} \mathrm{H}$ NMR $\left(300 \mathrm{MHz}, \mathrm{CDCl}_{3}\right) 7.31(\mathrm{~s}, 2 \mathrm{H}), 6.74(\mathrm{~s}, 2 \mathrm{H}), 2.19$ $(\mathrm{m}, 4 \mathrm{H}), 1.57(\mathrm{~m}, 4 \mathrm{H}), 1.29(\mathrm{~m}, 20 \mathrm{H}), 0.90(\mathrm{t}, 6 \mathrm{H}) .{ }^{13} \mathrm{C} \mathrm{NMR}\left(100 \mathrm{MHz}, \mathrm{CDCl}_{3}\right)$ 154.2, 145.7, 124.4, 120.5, 91.9, 32.1, 30.3, 29.7, 29.5, 29.4, 24.9, 22.9, 14.4. HRMS calcd for $\mathrm{C}_{26} \mathrm{H}_{38} \mathrm{Br}_{2} \mathrm{O}\left(\mathrm{M}^{+}\right)$524.1284, found 524.1291 .

1,4-epoxy-1,4-dihydro-6,7-dibromo-5,8-dioctylnaphthalene (10b) This compound was prepared by following the procedure as described for 10a, employing the following materials: 1,2,4,5-tetrabromo3,6-dioctylbenzene (9b) (6.38 g, $10.3 \mathrm{mmol})$, furan (11 mL), $n$-BuLi (1.6 M in hexane, $7.4 \mathrm{~mL}, 11.8$ $\mathrm{mmol})$, and toluene $(150 \mathrm{~mL})$. This reaction was carried out at $-30{ }^{\circ} \mathrm{C}$. The common workup and chromatography gave $4.2 \mathrm{~g}$ of $\mathbf{1 0 b}$ as a colorless solid (78\%). ${ }^{1} \mathrm{H}$ NMR (400 MHz, $\left.\mathrm{CDCl}_{3}\right) 7.03$ (s, $\left.2 \mathrm{H}\right)$, $5.76(\mathrm{~s}, 2 \mathrm{H}), 2.81(\mathrm{~m}, 4 \mathrm{H}), 1.50(\mathrm{~m}, 4 \mathrm{H}), 1.30(\mathrm{~m}, 20 \mathrm{H}) 0.90(\mathrm{t}, 6 \mathrm{H}) .{ }^{13} \mathrm{C} \mathrm{NMR}\left(100 \mathrm{MHz}, \mathrm{CDCl}_{3}\right)$ 
$147.8,142.9,135.1,124.7,82.0,35.0,32.1,30.0,29.8,29.6,29.4,22.9,14.3$. HRMS calcd for $\mathrm{C}_{26} \mathrm{H}_{38} \mathrm{Br}_{2} \mathrm{O}\left(\mathrm{M}^{+}\right)$524.1284, found 524.1279.

2,3-dibromo-5,8-dioctylnaphthalene (3c): Under $\mathrm{Ar}, \mathrm{TiCl}_{4}(11 \mathrm{~mL}, 100 \mathrm{mmol})$ was added carefully and slowly to a suspension of zinc dust $(10.2 \mathrm{~g}, 156 \mathrm{mmol})$ in anhydrous THF $(250 \mathrm{~mL})$ at $0{ }^{\circ} \mathrm{C}$. The resulting mixture was heated to reflux for 10 minutes. After cooling back to $0{ }^{\circ} \mathrm{C}$ by an ice-water bath, a solution of 10a $(7.75 \mathrm{~g}, 14.7 \mathrm{mmol})$ in anhydrous THF $(100 \mathrm{~mL})$ was added dropwise over a course of 2 hours. The reaction mixture was refluxed for 15 hours. After cooling, the reaction mixture was poured into $400 \mathrm{~g}$ crushed ice and extracted by $\mathrm{CH}_{2} \mathrm{Cl}_{2}$. The organic layer was washed with water and brine, and then dried over $\mathrm{MgSO}_{4}$, and concentrated in vacuo. Purification by column chromatography (silica gel, hexane) yielded a white solid (6.61g, 88\%). ${ }^{1} \mathrm{H}$ NMR (400 MHz) 8.33 (s, 2H), 7.28 (s, 2H), 2.97 (t, 4H), $1.72(\mathrm{~m}, 4 \mathrm{H}), 1.42(\mathrm{~m}, 4 \mathrm{H}) 1.33(\mathrm{~m}, 16 \mathrm{H}), 0.91(\mathrm{t}, 6 \mathrm{H}) .{ }^{13} \mathrm{C} \mathrm{NMR}\left(100 \mathrm{MHz}, \mathrm{CDCl}_{3}\right)$ 136.5, 132.5, 129.6, 127.1, 121.7, 33.0, 32.1, 30.9, 29.9, 29.7, 29.5, 22.9, 14.3. HRMS calcd for $\mathrm{C}_{26} \mathrm{H}_{38} \mathrm{Br}_{2}\left(\mathrm{M}^{+}\right)$ 508.1335 , found 508.1352 .

2,3-dibromo-1,4-dioctylnaphthalene (3d): This compound was prepared by following the procedure as described for 3c, employing the following materials: 10b $(5.32 \mathrm{~g}, 10.1 \mathrm{mmol}), \mathrm{TiCl}_{4}(7.6 \mathrm{~mL}, 69.3$ mmol), zinc ( $7.15 \mathrm{~g}, 0.11 \mathrm{~mol})$, THF $(200 \mathrm{~mL})$. The usual workup, chromatography and recrystallization (methanol/THF) gave $4.9 \mathrm{~g}$ of $\mathbf{3 d}$ as a white solid $(95 \%) .{ }^{1} \mathrm{H}$ NMR $\left(400 \mathrm{MHz}, \mathrm{CDCl}_{3}\right) 8.05(\mathrm{dd}, 2 \mathrm{H})$, $7.55(\mathrm{dd}, 2 \mathrm{H}), 3.34(\mathrm{t}, 4 \mathrm{H}), 1.66(\mathrm{~m}, 4 \mathrm{H}), 1.54(\mathrm{~m}, 4 \mathrm{H}), 1.37(\mathrm{~m}, 16 \mathrm{H}), 0.91(\mathrm{t}, 6 \mathrm{H}) .{ }^{13} \mathrm{C}$ NMR $(100$ $\left.\mathrm{MHz}, \mathrm{CDCl}_{3}\right)$ 139.2, 131.9, 126.8, 125.7, 125.5, 35.1, 32.1, 30.3, 29.6, 29.5, 22.9, 14.4. HRMS calcd for $\mathrm{C}_{26} \mathrm{H}_{38} \mathrm{Br}_{2}\left(\mathrm{M}^{+}\right)$508.1335, found 508.1337. 


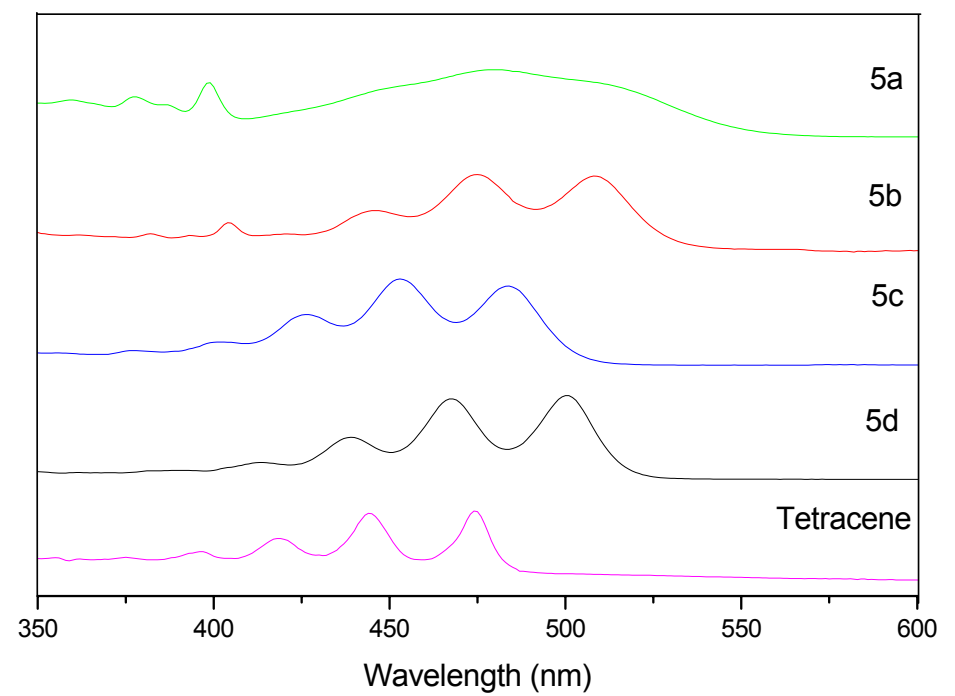

Figure S1. UV-vis absorption spectra of tetracene and 5a-d measured in $\mathrm{CH}_{2} \mathrm{Cl}_{2}$.

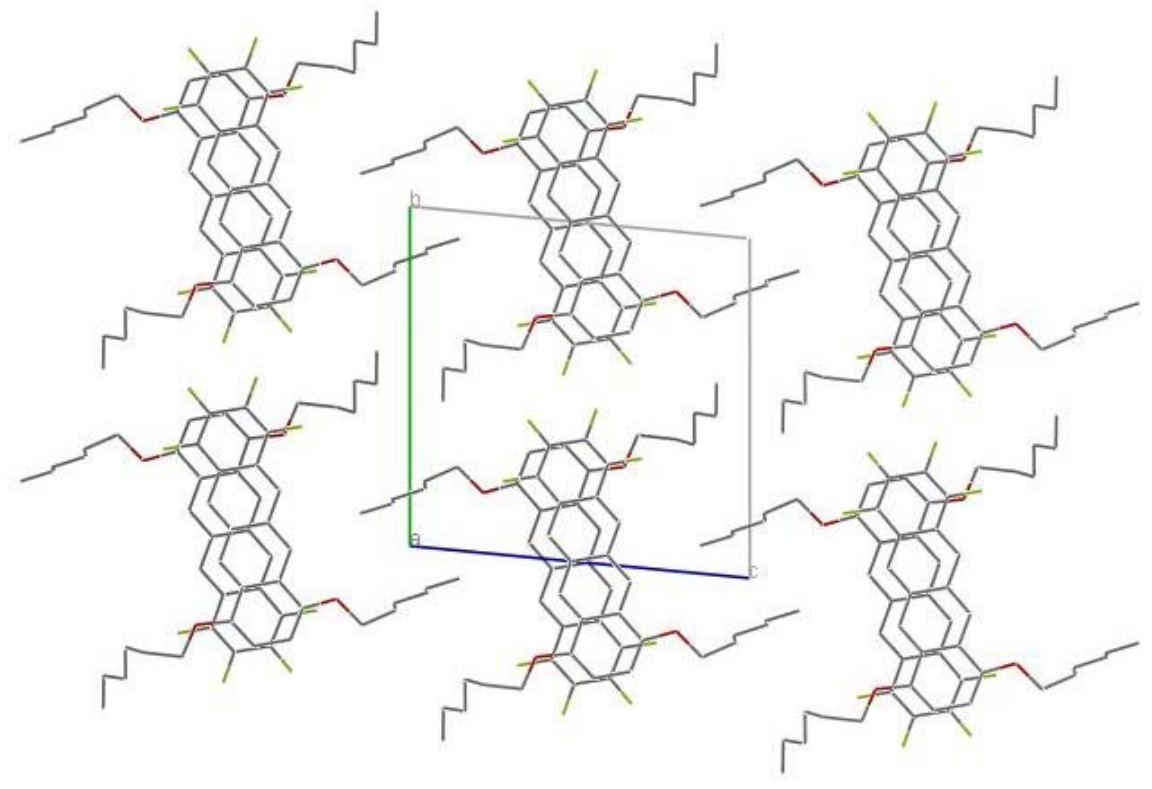

Figure S2. Packing diagram of 5a (view along the $a$-axis) 


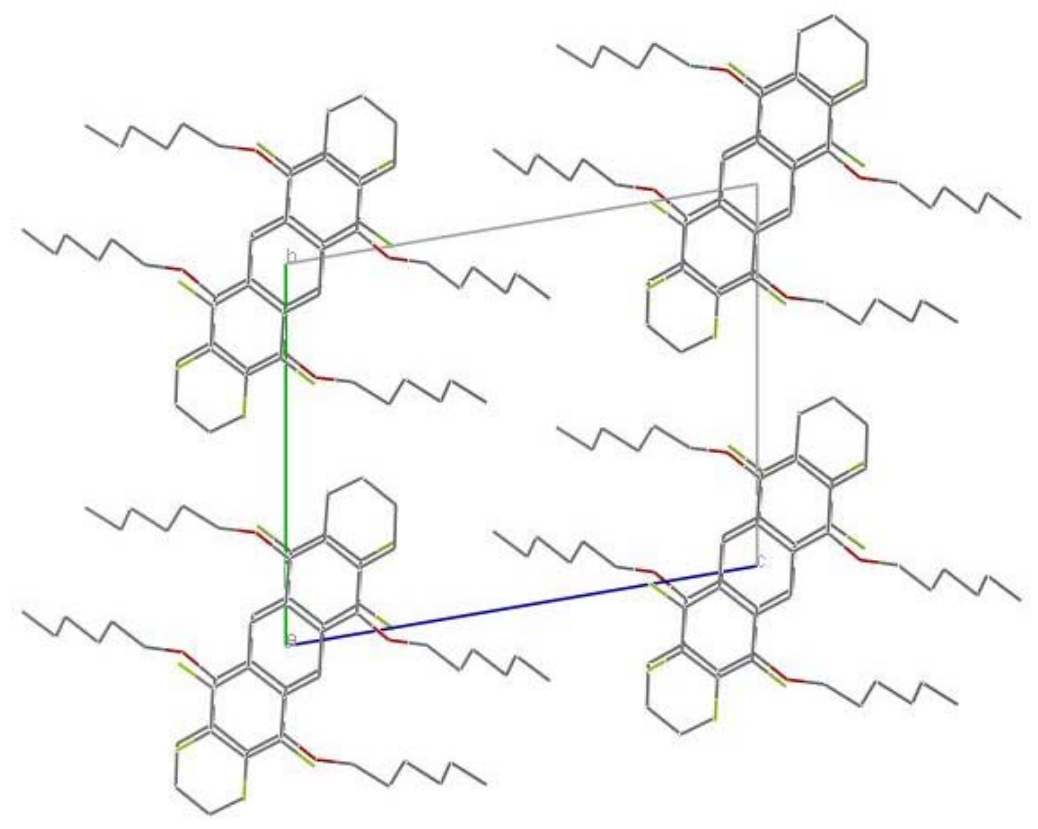

Figure S3. Packing diagram of $\mathbf{5 b}$ (view along the $a$-axis)

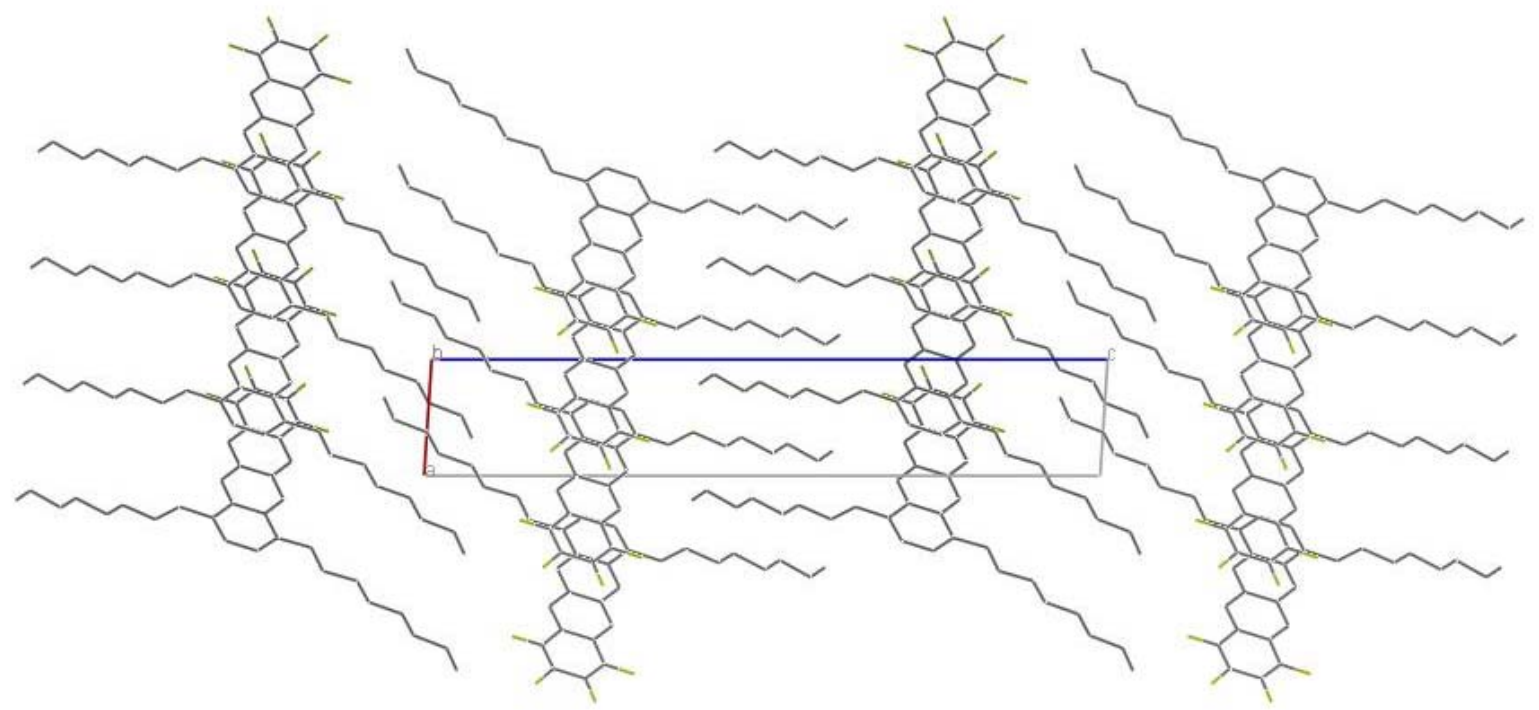

Figure S4. Packing diagram of 5c (view along the $b$-axis) 


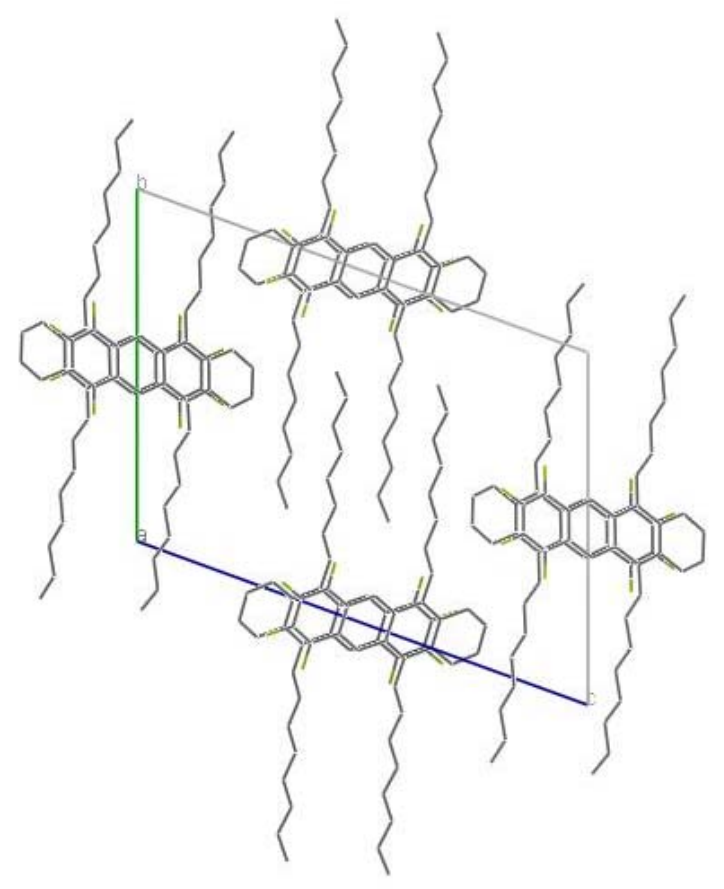

Figure S5. Packing diagram of $\mathbf{5 d}$ (view along the $a$-axis)

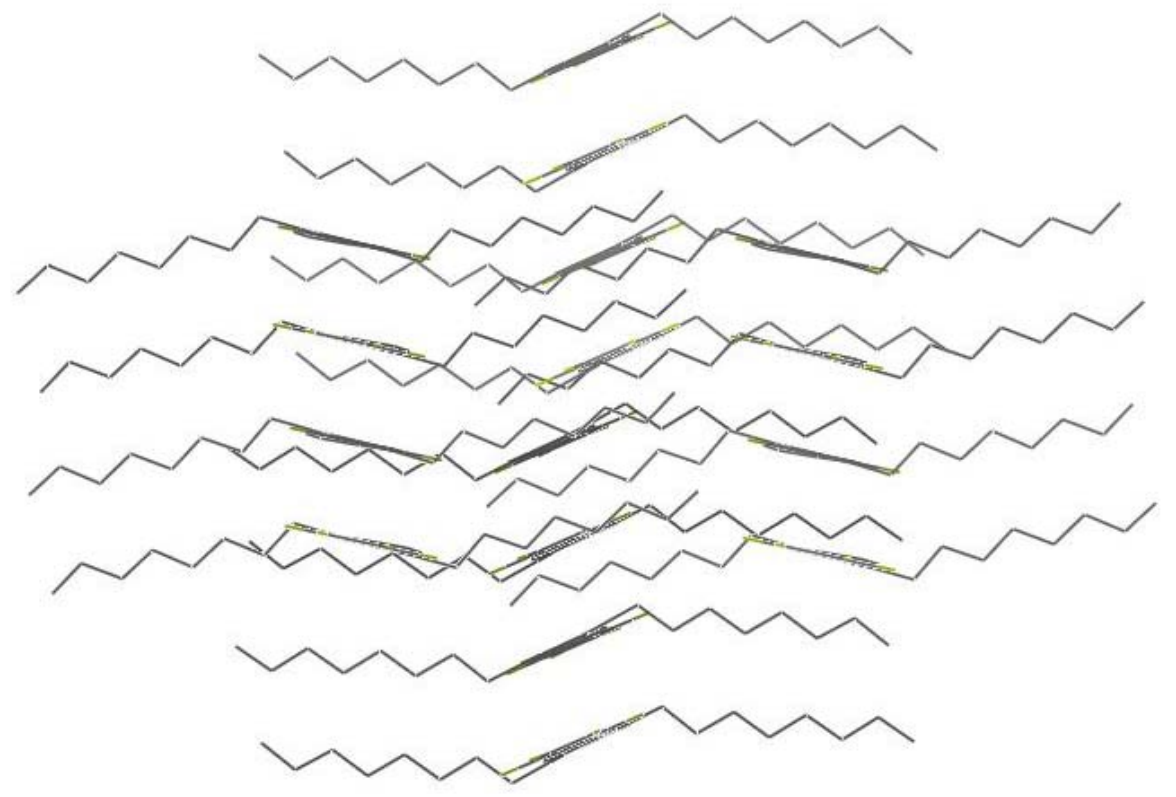

Figure S6. Packing diagram of 5d, showing the $141^{\circ}$ angle between molecules in neighboring crystal packing columns.

\section{References:}

(1) Yang, G. Y.; Hanack, M.; Lee, Y. W.; Chen, Y.; Lee, M. K. Y.; Dini, D. Chem. Eur. J. 2003, 9, 2758. 
(2) Bailey, D.; Williams, V. E.; Tetrahedron Lett. 2004, 45, 2511.

(3) Blatter, K.; Schlüter, A.-D. Chem. Ber. 1989, 122, 1351.

(4) McKeown, N. B.; Chambrier, I.; Cook, M. J. J. Chem. Soc. Perkin Trans. 1 1990, 1169.

(5) LeHoullier, C. S.; Gribble, G. W. J. Org. Chem. 1983, 48, 2364.

(6) Gribble, G. W.; Allen, R. W.; LeHoullier, C. S.; Eaton, J. T.; Easton, N. R.; Slayton, R. I. J. Org. Chem. 1981, 46, 1025. 
${ }^{1} \mathrm{H},{ }^{19} \mathrm{~F}$ and ${ }^{13} \mathrm{C}$ NMR spectra of $\mathbf{4 a}$
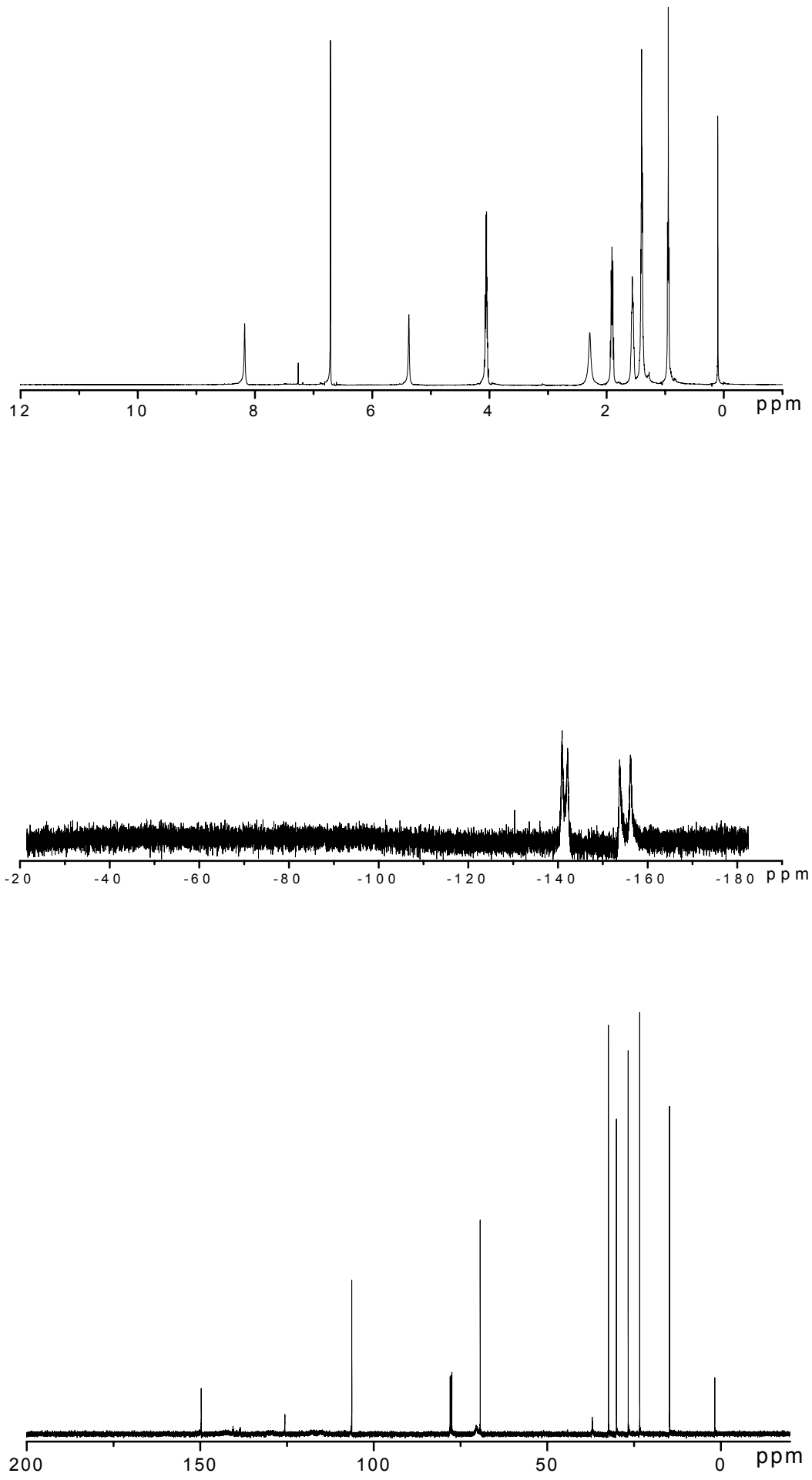
${ }^{1} \mathrm{H},{ }^{19} \mathrm{~F}$ and ${ }^{13} \mathrm{C}$ NMR spectra of $\mathbf{5 a}$
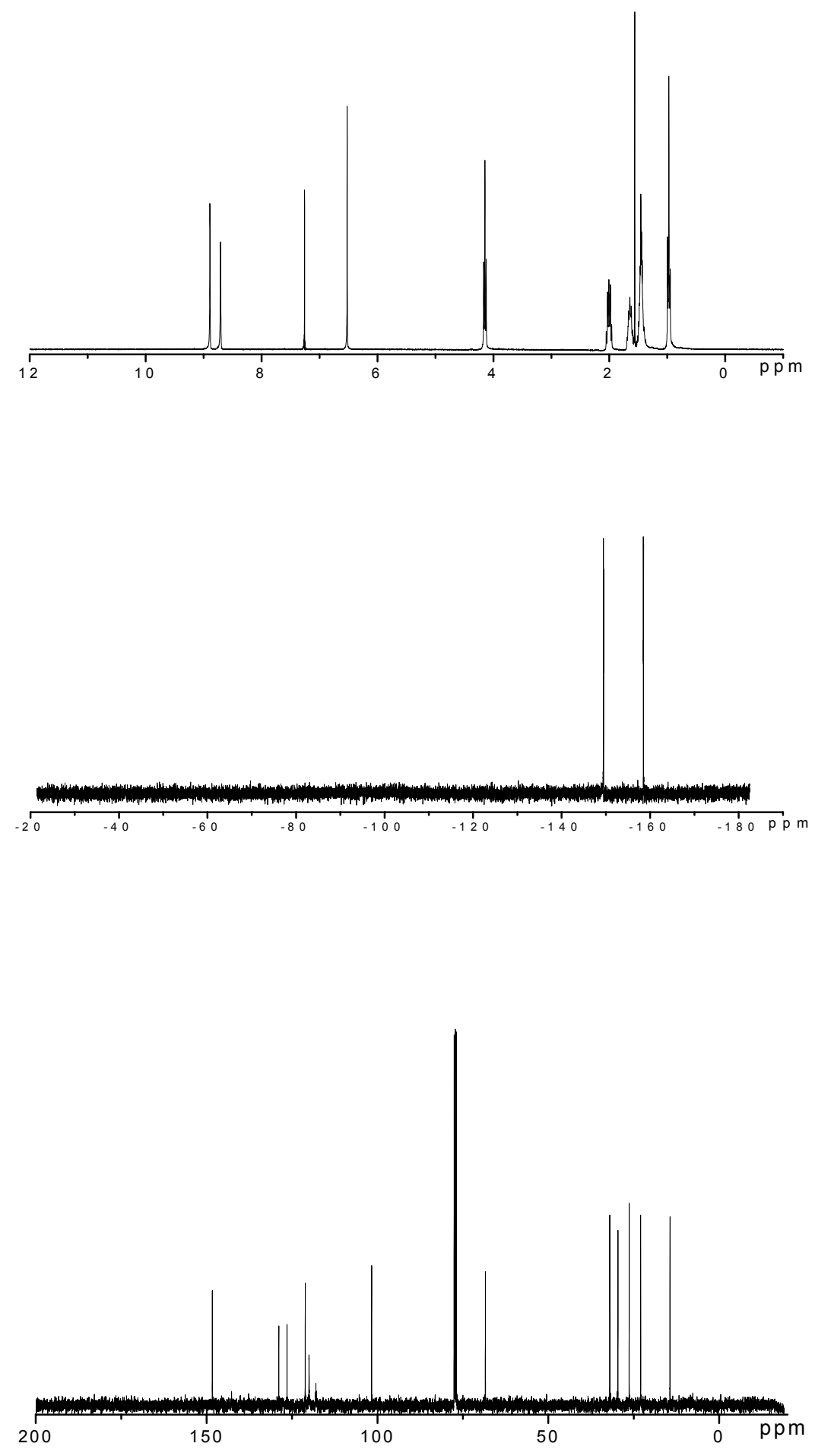
${ }^{1} \mathrm{H},{ }^{19} \mathrm{~F}$ and ${ }^{13} \mathrm{C}$ NMR spectra of $\mathbf{4 b}$
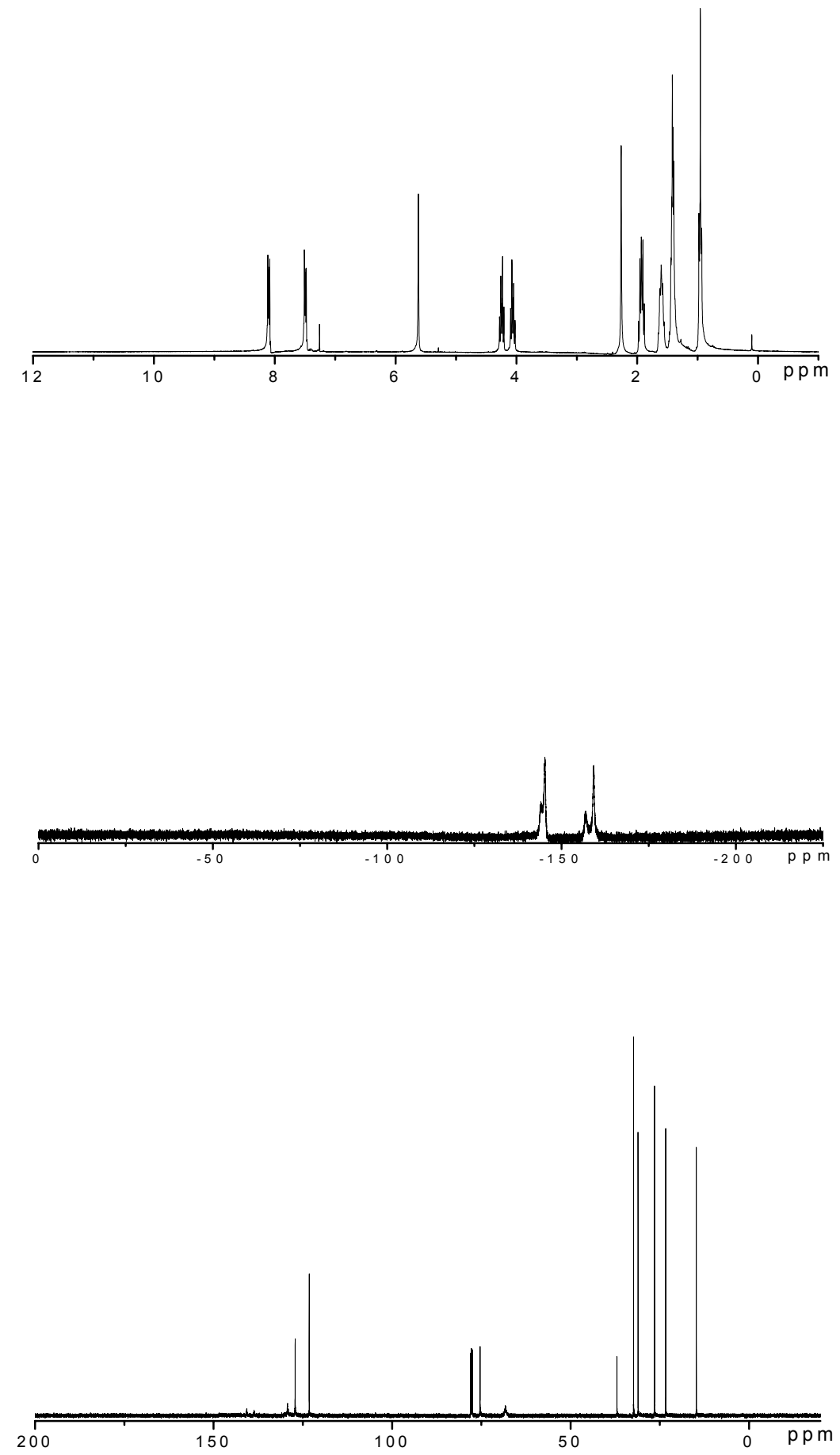
${ }^{1} \mathrm{H},{ }^{19} \mathrm{~F}$ and ${ }^{13} \mathrm{C}$ NMR spectra of $\mathbf{5 b}$
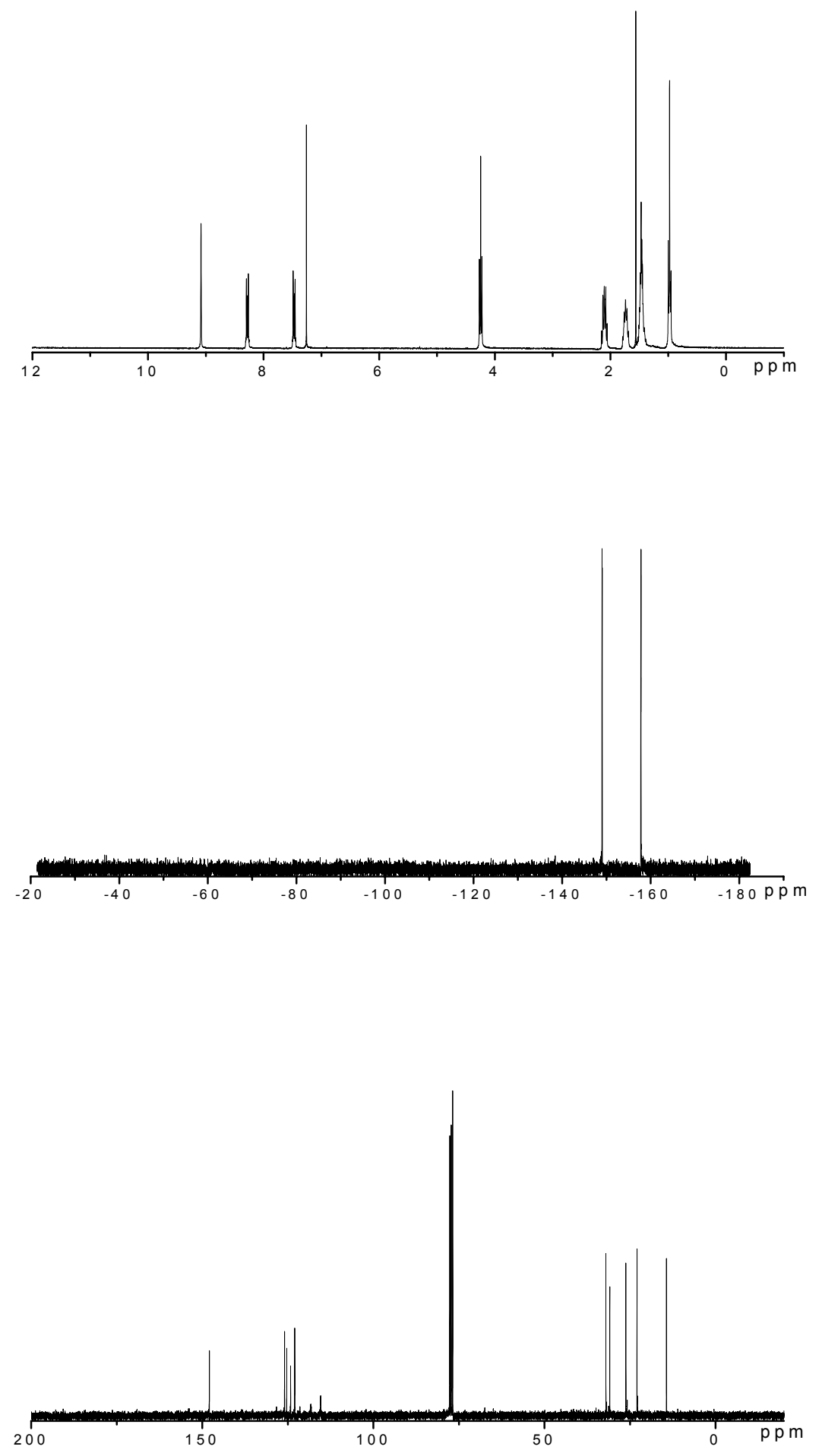
${ }^{1} \mathrm{H},{ }^{19} \mathrm{~F}$ and ${ }^{13} \mathrm{C}$ NMR spectra of $\mathbf{4 c}$
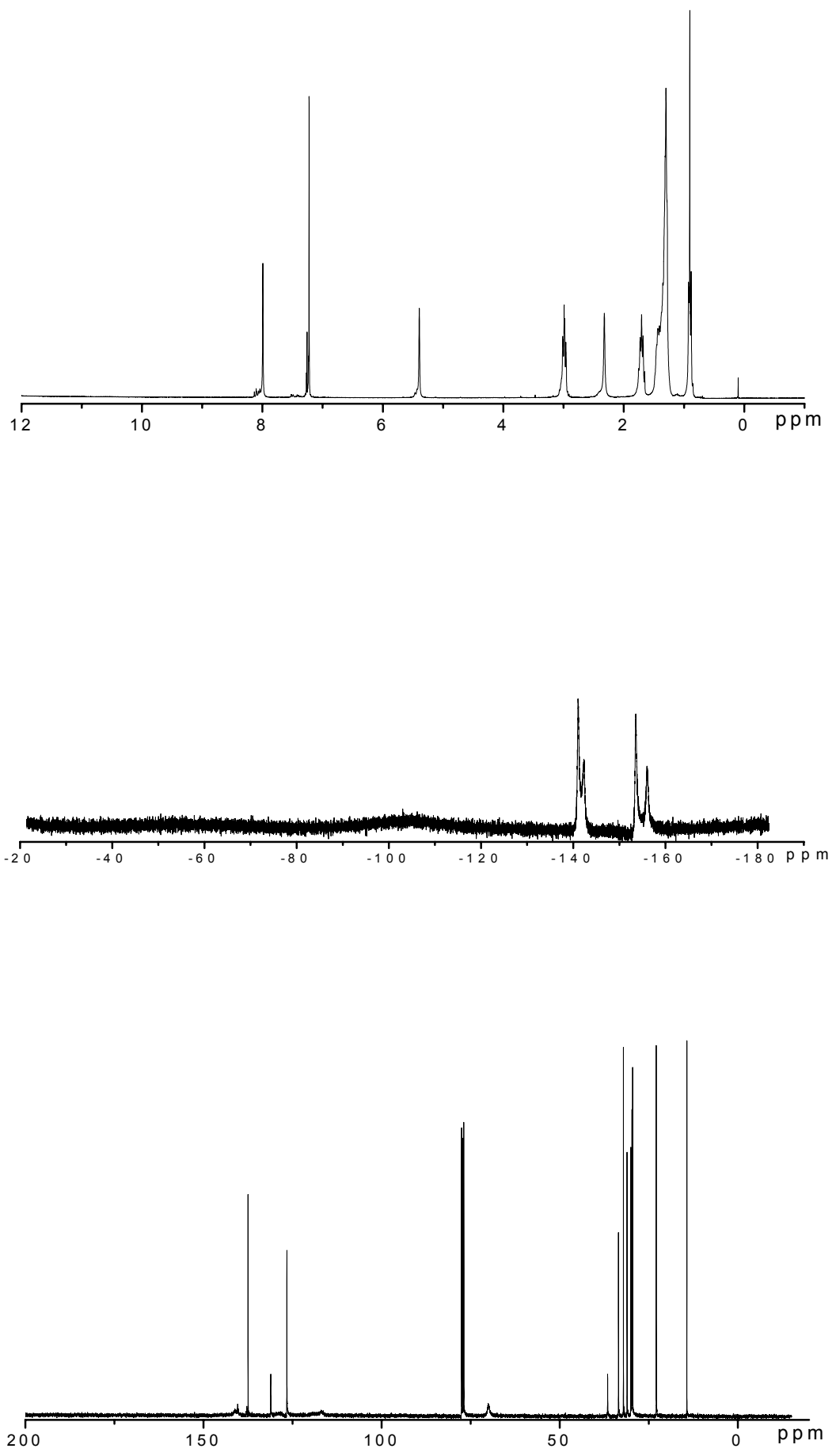
${ }^{1} \mathrm{H},{ }^{19} \mathrm{~F}$ and ${ }^{13} \mathrm{C}$ NMR spectra of $\mathbf{5 c}$
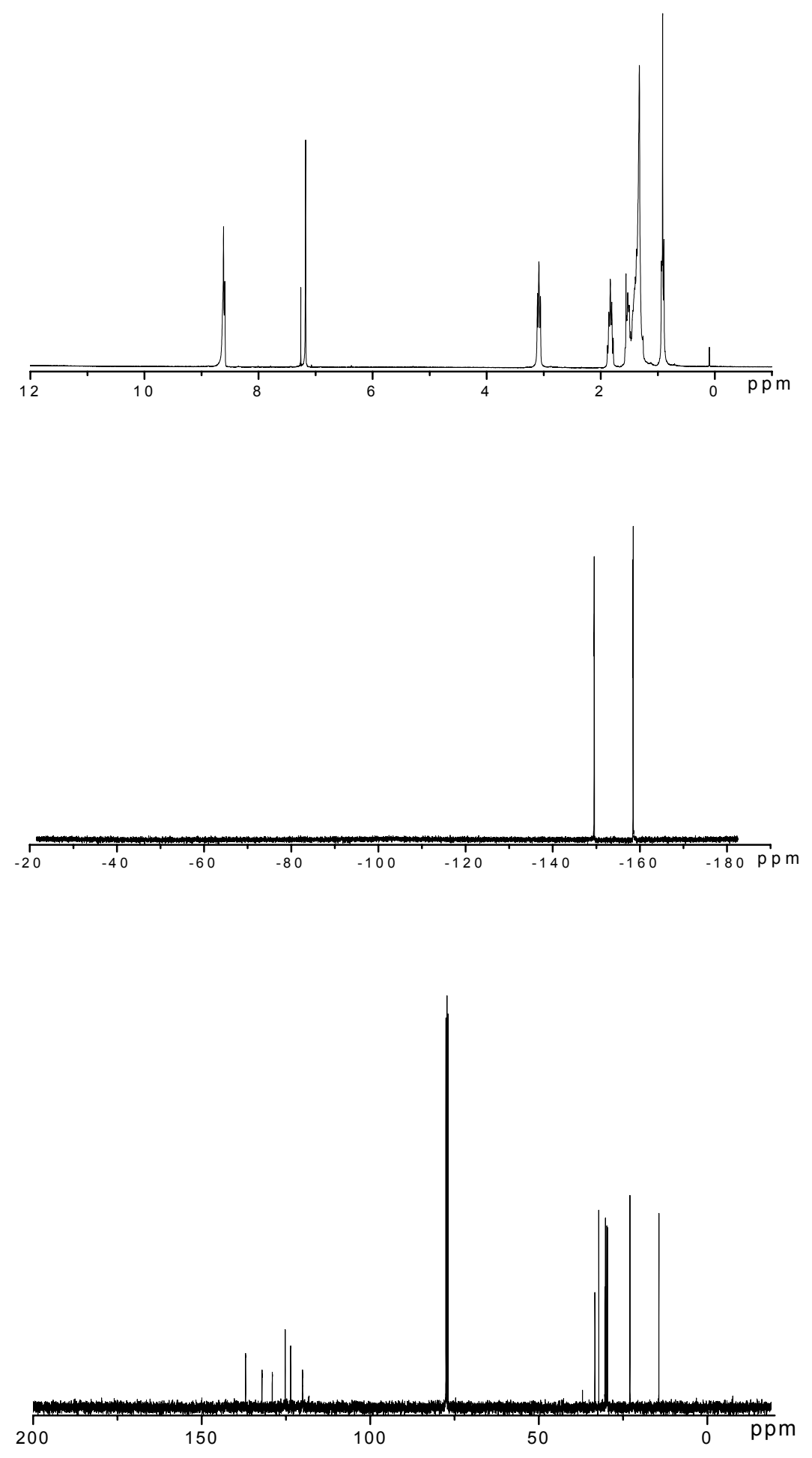
${ }^{1} \mathrm{H},{ }^{19} \mathrm{~F}$ and ${ }^{13} \mathrm{C}$ NMR spectra of $\mathbf{4 d}$
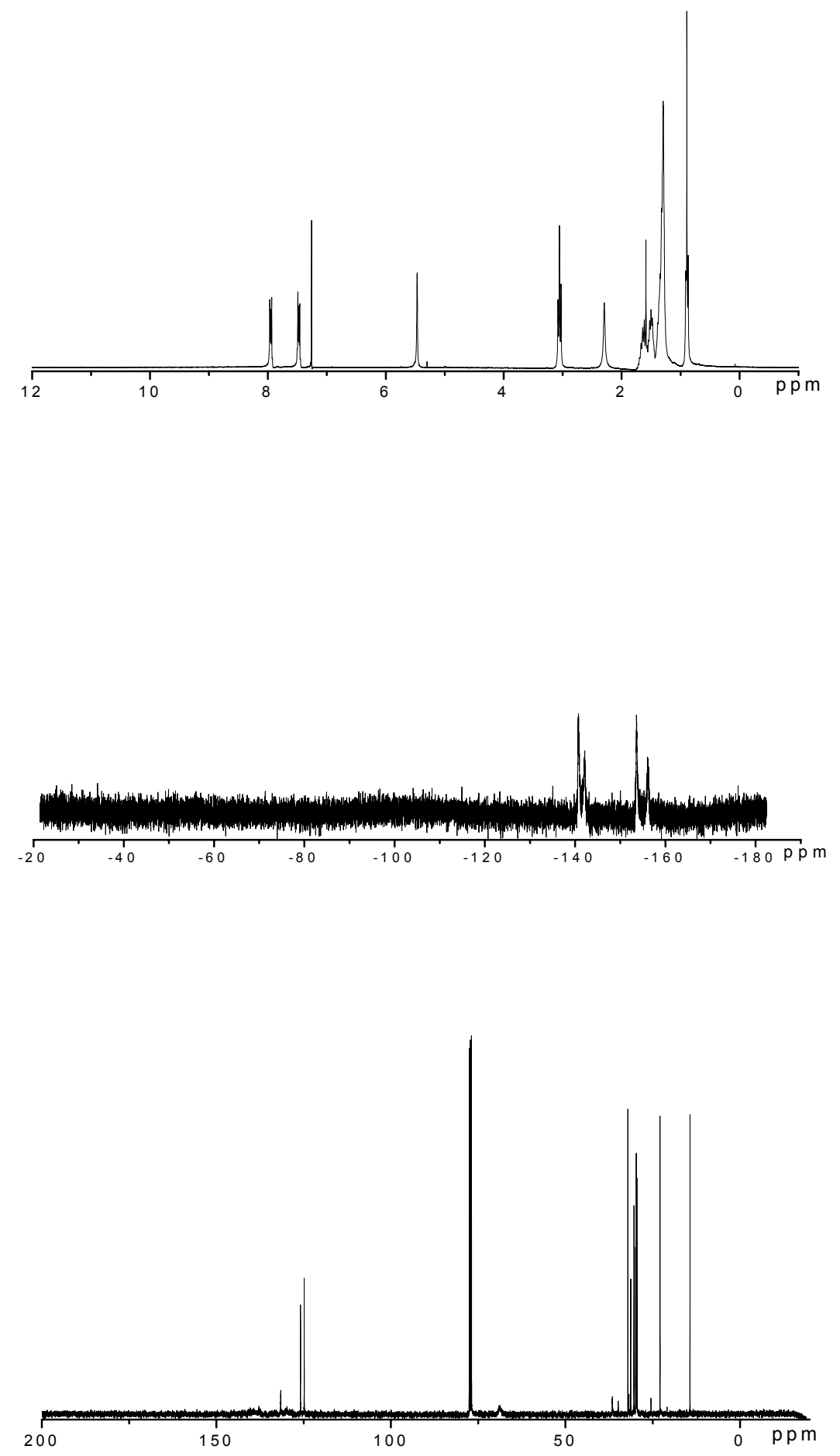
${ }^{1} \mathrm{H},{ }^{19} \mathrm{~F}$ and ${ }^{13} \mathrm{C}$ NMR spectra of $\mathbf{5 d}$
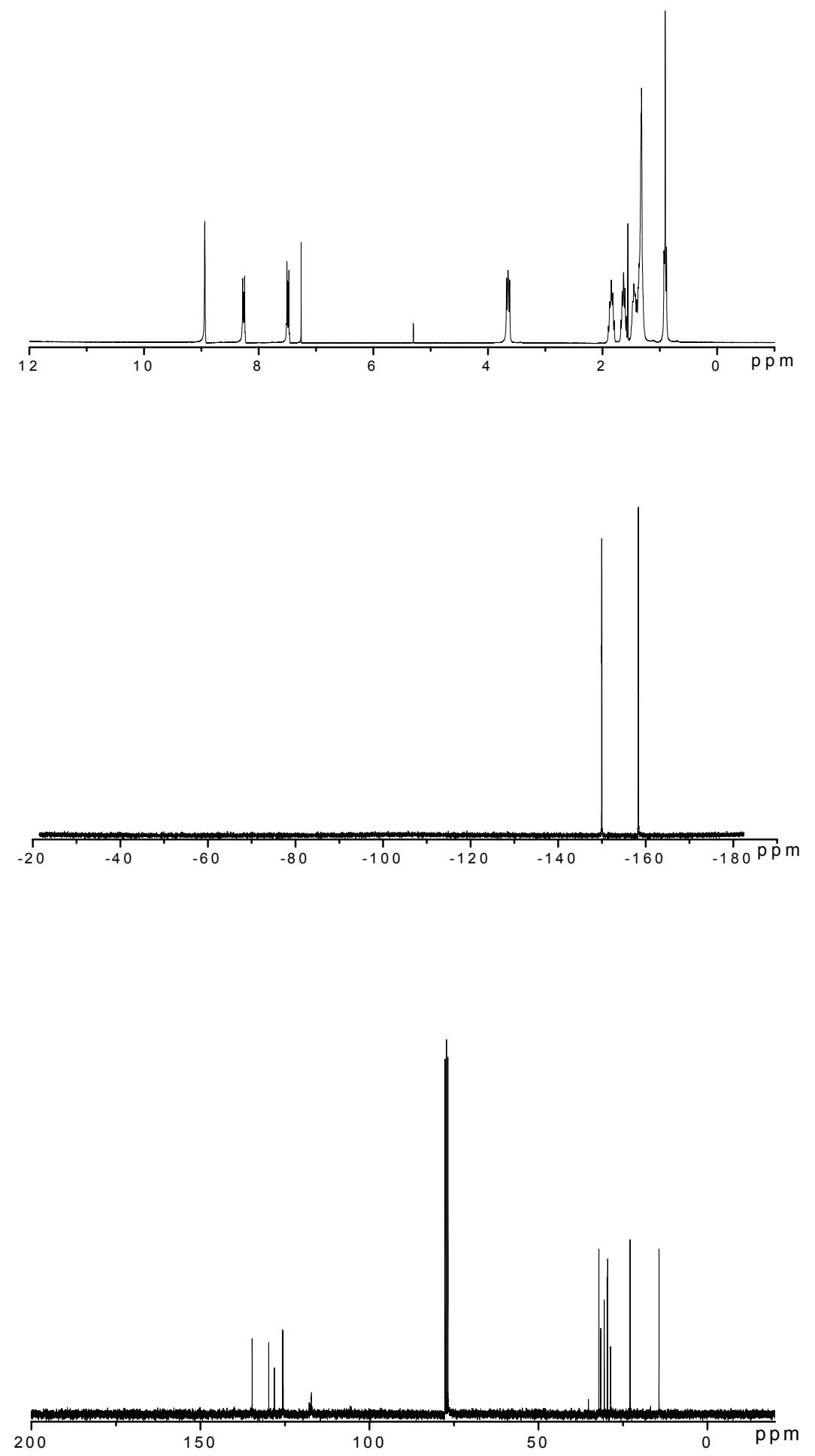
${ }^{1} \mathrm{H}$ and ${ }^{13} \mathrm{C}$ NMR spectra of $\mathbf{3 a}$
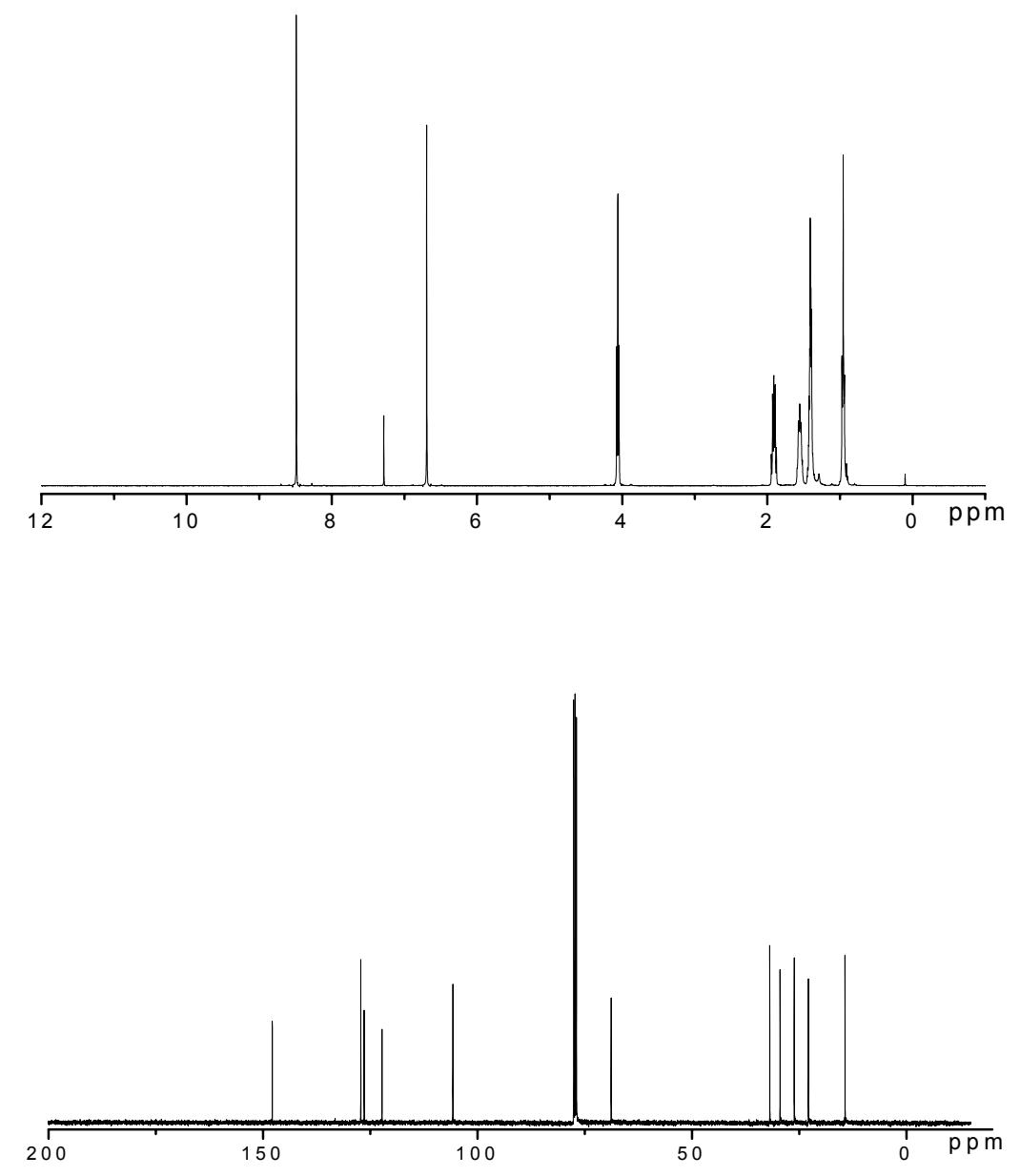

${ }^{1} \mathrm{H}$ and ${ }^{13} \mathrm{C}$ NMR spectra of 8

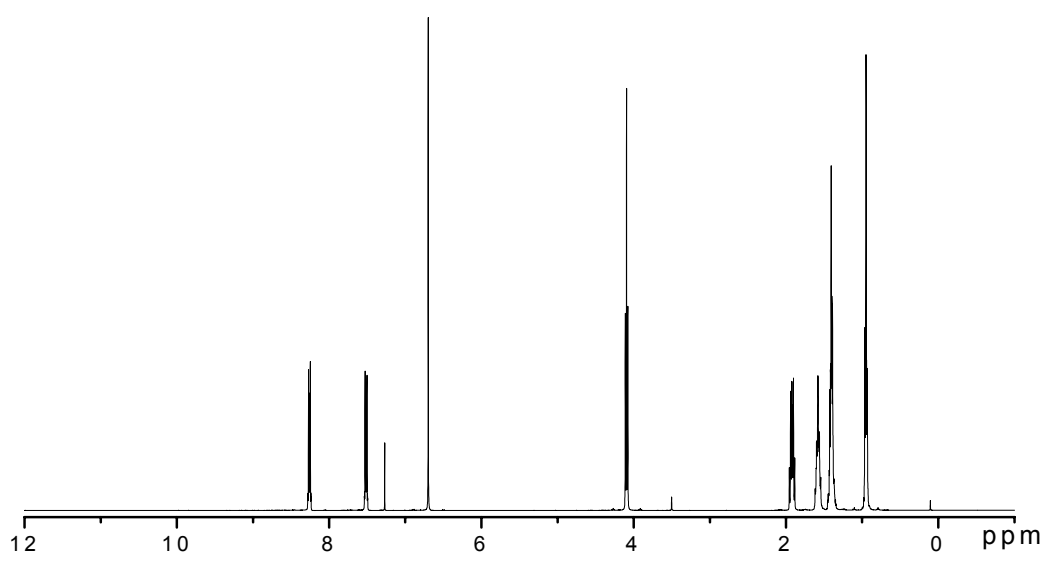




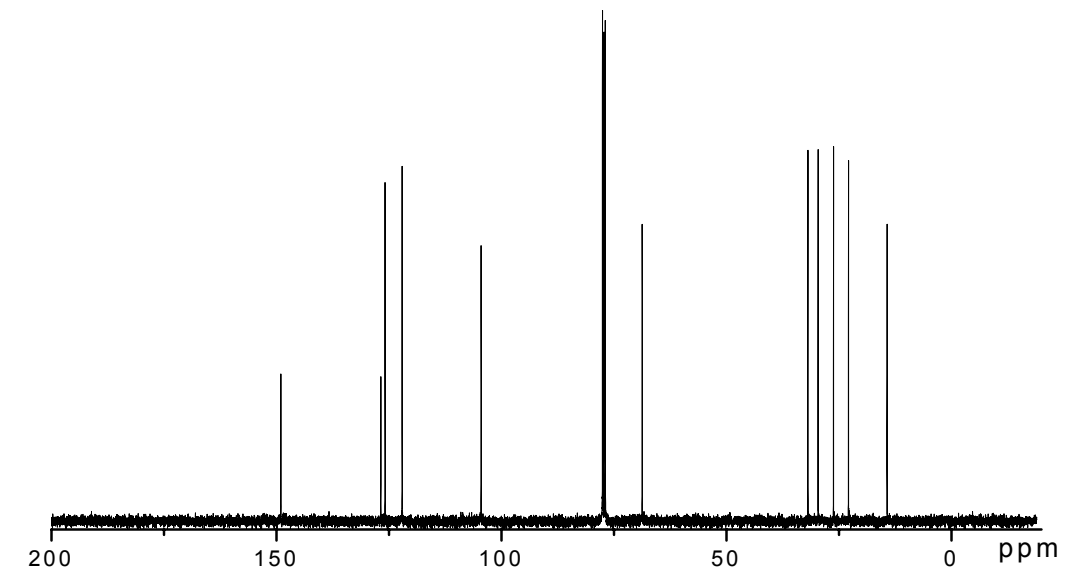

${ }^{1} \mathrm{H}$ and ${ }^{13} \mathrm{C}$ NMR spectra of $\mathbf{3 b}$
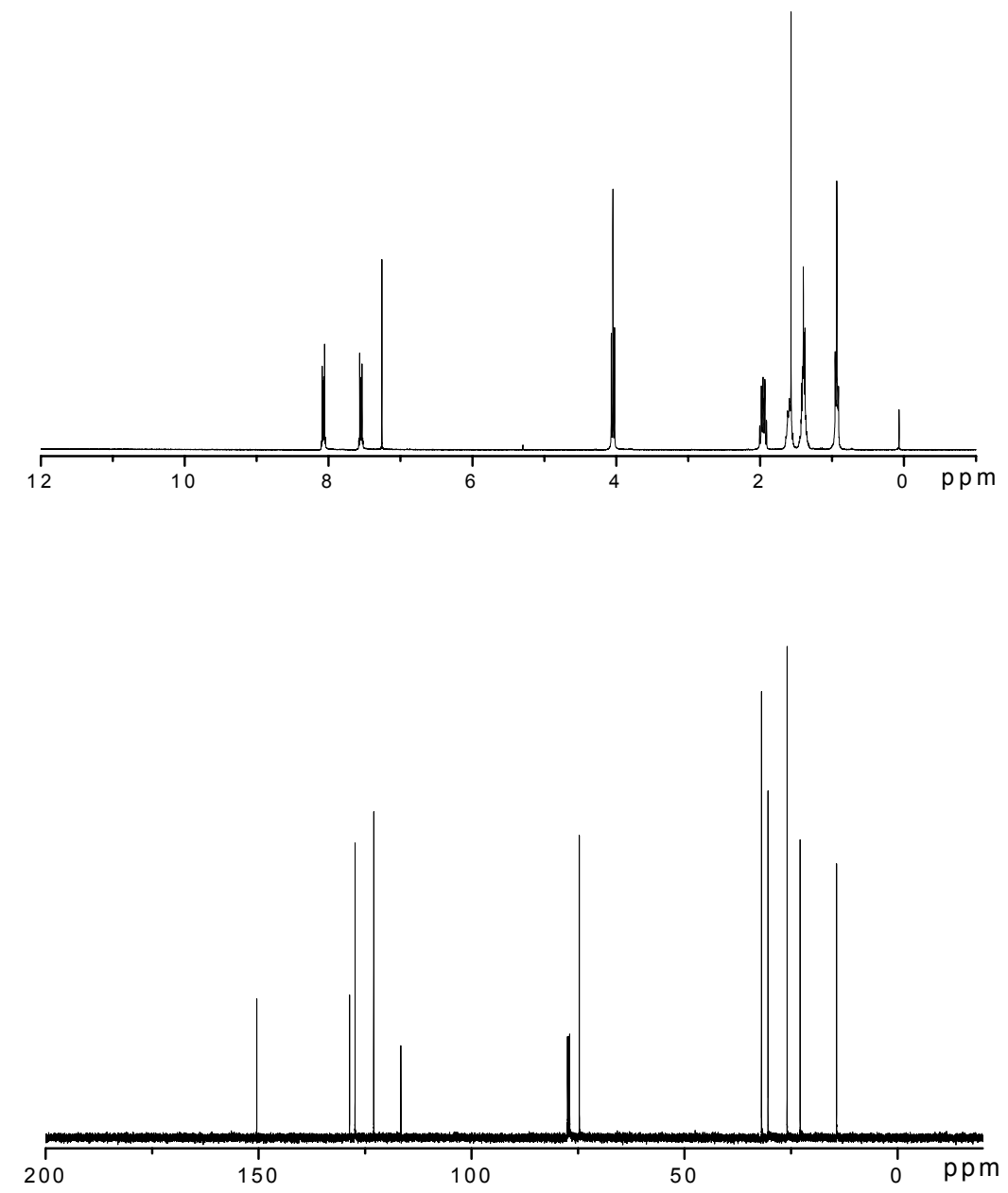
${ }^{1} \mathrm{H}$ and ${ }^{13} \mathrm{C}$ NMR spectra of $\mathbf{1 0 a}$
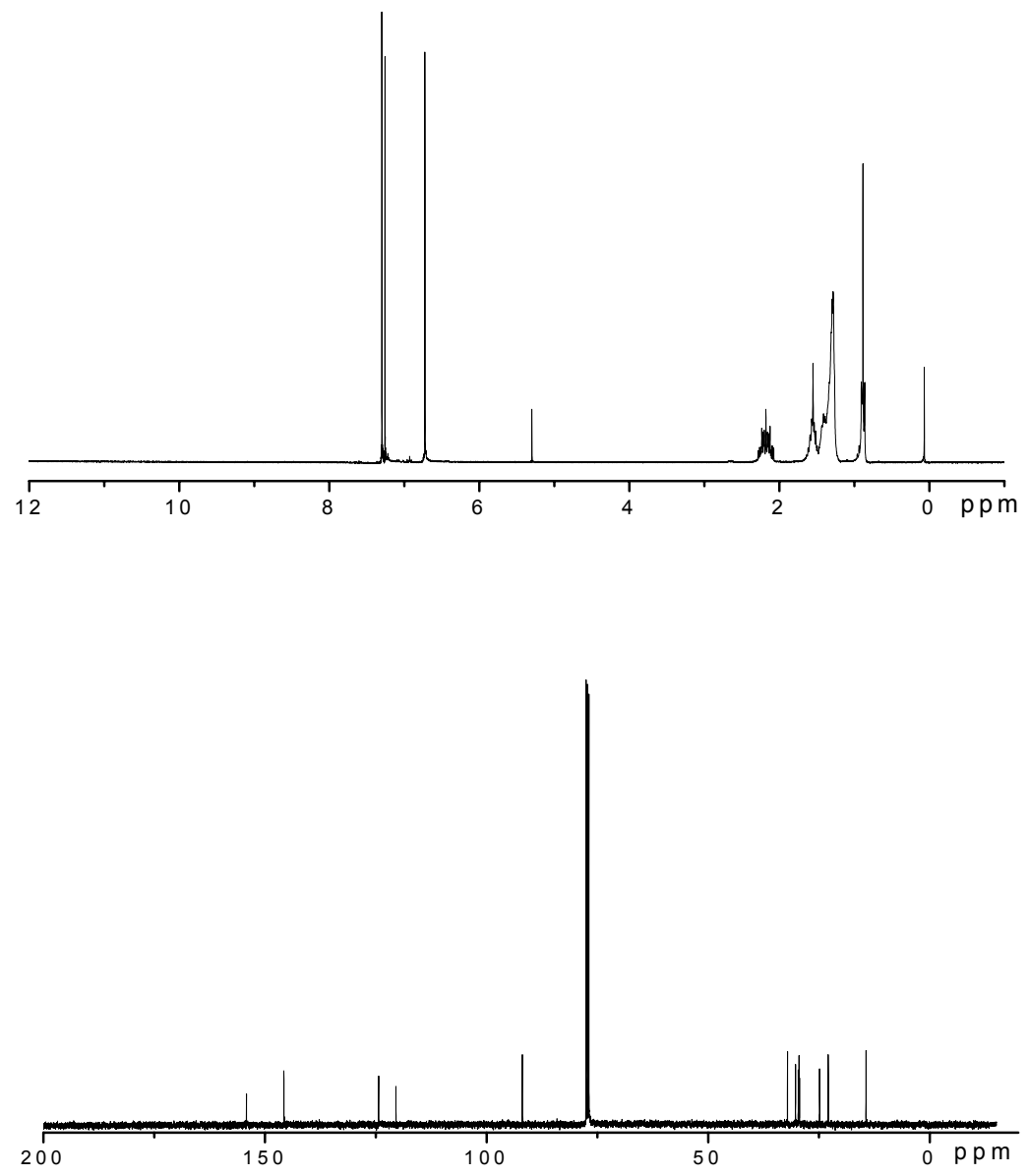

${ }^{1} \mathrm{H}$ and ${ }^{13} \mathrm{C}$ NMR spectra of $\mathbf{3 c}$

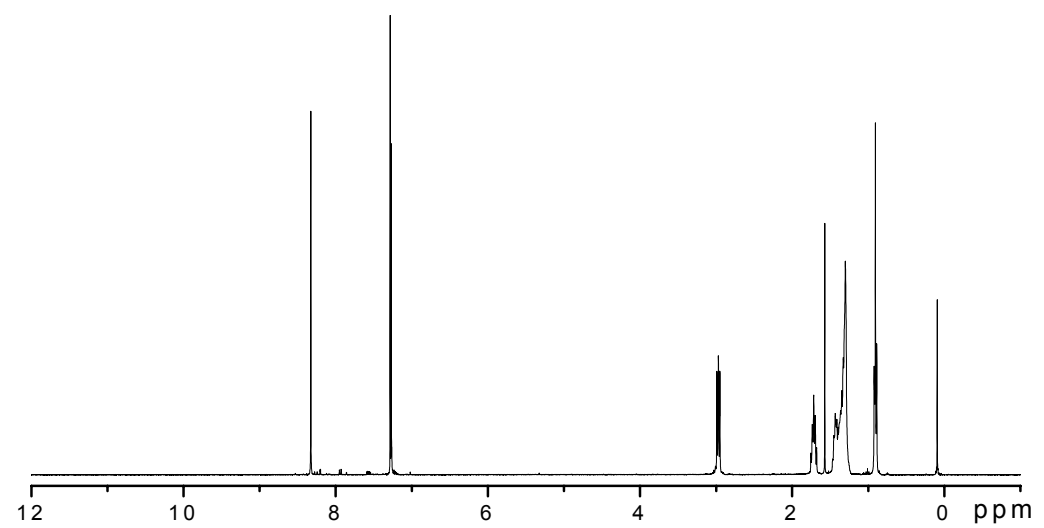




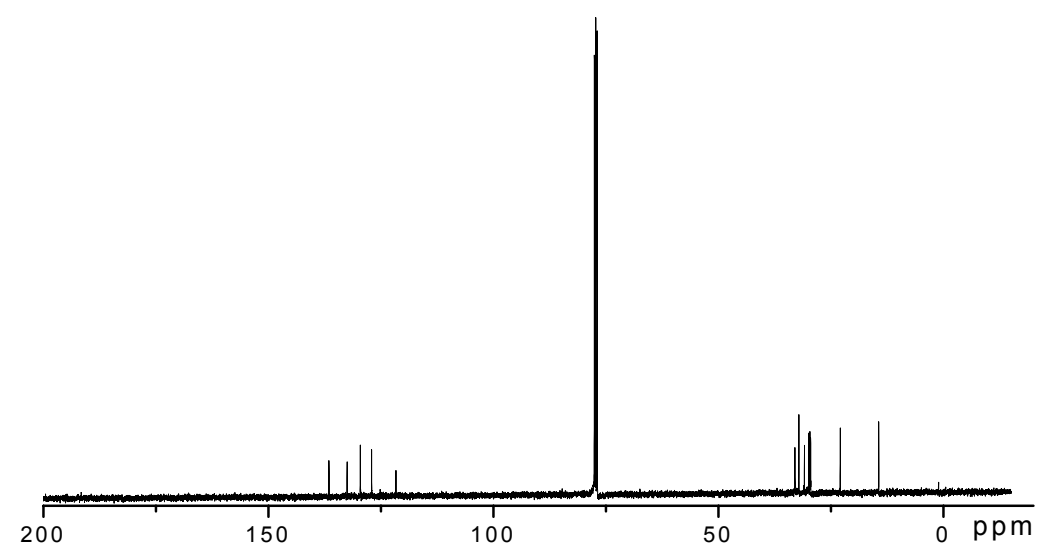

${ }^{1} \mathrm{H}$ and ${ }^{13} \mathrm{C}$ NMR spectra of $\mathbf{1 0 b}$
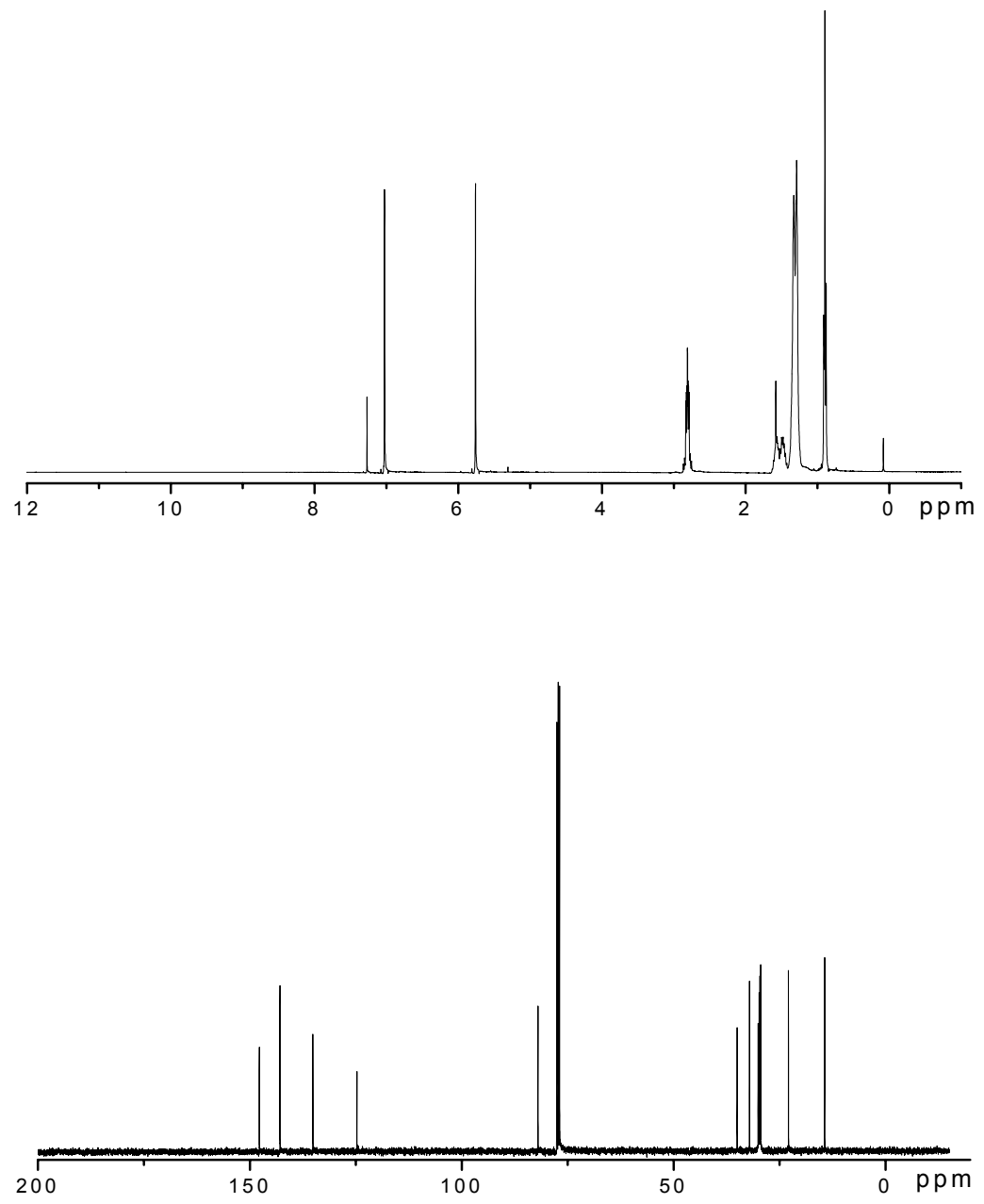
${ }^{1} \mathrm{H}$ and ${ }^{13} \mathrm{C}$ NMR spectra of $\mathbf{3 d}$
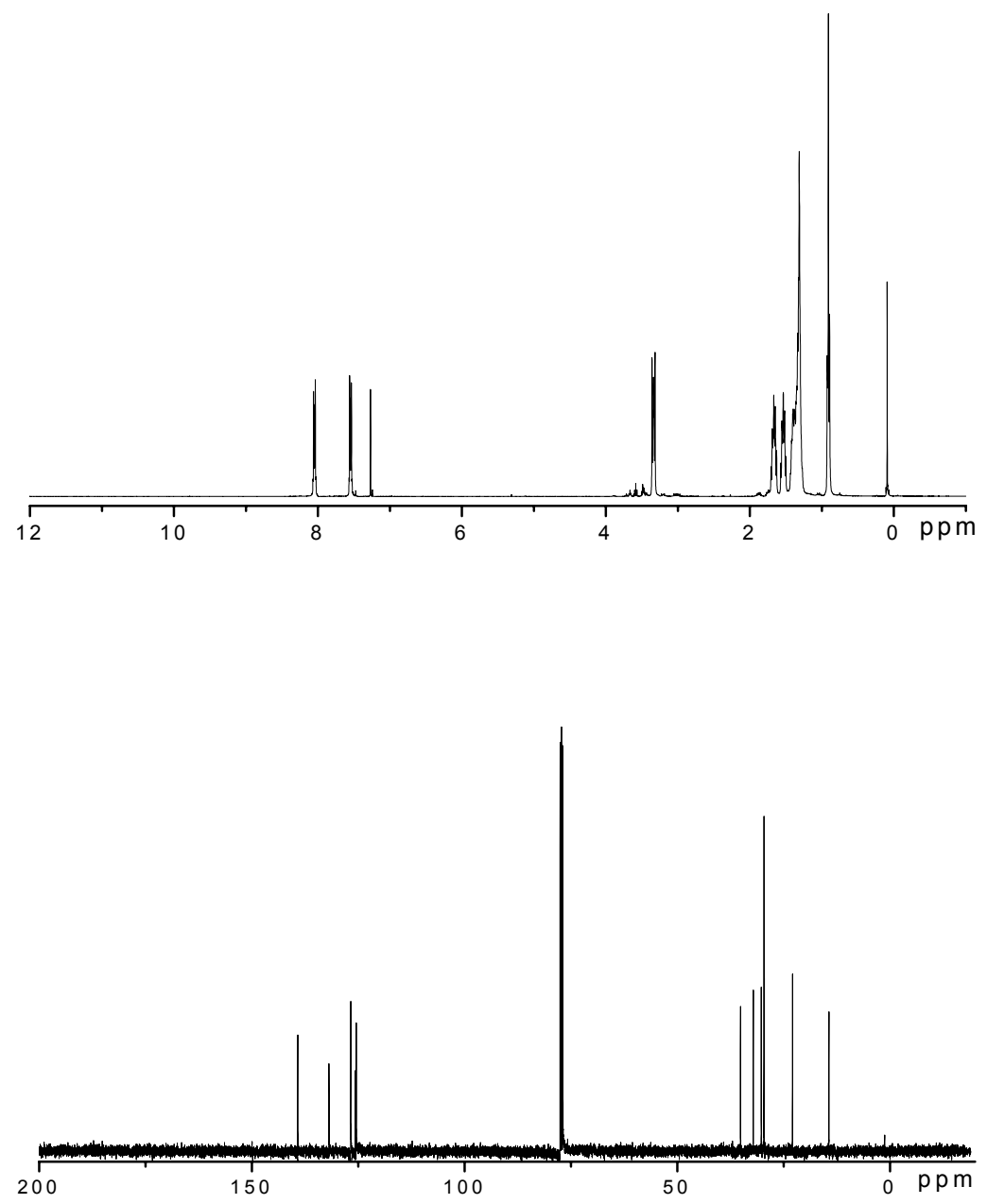